\title{
PROCESSES OF CATALYTIC OXIDATION FOR THE PRODUCTION OF CHEMICALS FROM SOFTWOOD BIOMASS
}

B.N. Kuznetsov $^{1,2^{*}}$, I.G. Sudakova ${ }^{1}$, N.V. Garyntseva ${ }^{1}$, V.E. Tarabanko ${ }^{1}$, O.V. Yatsenkova ${ }^{1}$, L. Djakovitch ${ }^{3}$, F. Rataboul ${ }^{3}$

${ }^{1}$ Institute of Chemistry and Chemical Technology SB RAS, FRC KSC SB RAS, 660036, Krasnoyarsk, Russia

${ }^{2}$ Siberian Federal University, Krasnoyarsk, Russia

${ }^{3}$ IRCELYON, Lyon, F-69626 Villeurbanne Cedex, France

*E-mail: bnk@icct.ru; inm@icct.ru, +7-391-205-19-42

\section{Abstract}

Two alternative routes of softwood catalytic oxidative fractionation on cellulose products and fine chemicals are assessed.

We suggested to use the process of larch wood peroxide oxidation in the medium acetic acid - water at temperatures $70-100{ }^{\circ} \mathrm{C}$ in the presence of soluble catalyst $\left(\mathrm{NH}_{4}\right)_{6} \mathrm{Mo}_{7} \mathrm{O}_{24}$ to produce microcrystalline cellulose ( $35.0 \mathrm{wt} \%$ on wood), microfibrillated cellulose $(7.5 \mathrm{wt} \%$ on wood), nanocrystalline cellulose (3.7 wt \% on wood) and low molecular weight organic compounds ( $20 \mathrm{wt} \%$ on wood). The developed process reduces the number of technological stages and increase an environmentally safety of nanocelluloses production from wood, compared to traditional technologies.

Another suggested process of softwood (pine and larch) fractionation on vanillin (up to $4.7 \mathrm{wt} \%$ on wood) and cellulose (up to $34.6 \mathrm{wt} \%$ on wood) is based on wood oxidation by oxygen in water-alkaline medium at temperatures $160-180{ }^{\circ} \mathrm{C}$ in the presence of suspended catalyst $\mathrm{Cu}(\mathrm{OH})_{2}$. The further acid conversion of cellulose by $2 \% \mathrm{H}_{2} \mathrm{SO}_{4}$ at $180{ }^{\circ} \mathrm{C}$ produces levulinic acid with the yield up to $9.7 \mathrm{wt} \%$ on wood.

The integration of the processes of dihydroquercetin and arabinogalactan extraction isolation from larch wood, oxidation of extracted wood by oxygen to vanillin and cellulose in the presence of catalyst $\mathrm{Cu}(\mathrm{OH})_{2}$, acid catalyzed conversion of cellulose to levulinic acid and arabinogalactan hydrolysis over solid acid catalyst to arabinose and galactose leads to an increase in the number of target products.

FTIR, XRD, SEM, AFM solid state ${ }^{13} \mathrm{C} \mathrm{CP} / \mathrm{MAS}$ and chemical methods were used for characterization of cellulose products. Organic compounds were identified by GC, HPLC and GC-MS methods.

The two alternative schemes of larch wood catalytic oxidative biorefinery to produce nanocelluloses and fine chemicals have been developed. 
Keywords: softwood, oxidation, catalysts, chemicals, biorefinery.

\section{Introduction}

The huge resources of lignocellulosic biomass are presented by softwood which can be used as an important renewable feedstock for production of valuable chemicals and biofuels.

Lignocellulosic biomass mainly consists of cellulose, hemicelluloses and lignin [1,2]. These plant polymers are structured in plant cells in a complex way, and the lignocellulosic biomass is quite resistant to chemical reagents and enzymes. Therefore, in industrial pulp production processes, chemically aggressive and environmentally hazardous reagents, elevated temperatures and pressures are used $[3,4]$. Traditional catalysts for hydrolysis processes are corrosive and environmentally hazardous mineral acids [5].

Current research trends in the development of new environmentally friendly high-tech processes of lignocellulosic biomass conversion into valuable chemicals are associated with the use of solid catalyst, organic solvents and "green" reagents [6 - 10].

The processes of organosolv delignification in the presence of environmentally safe oxidants, like oxygen and hydrogen peroxide, has drawn a lot of attention [11- 13]. The new organosolv processes can be successfully used for the wood fractionation on cellulose and soluble lignin for the purpose of their further processing to chemicals and biofuels.

Catalysts based on transition metals ( $\mathrm{W}^{\mathrm{VI}}, \mathrm{Mo}^{\mathrm{VI}}, \mathrm{V}^{\mathrm{V}}, \mathrm{Cu}^{\mathrm{II}}, \mathrm{Fe}^{\mathrm{III}}, \mathrm{Mn}^{\mathrm{II}, \mathrm{III}}, \mathrm{Co}^{\mathrm{II}}, \mathrm{Zr}^{\mathrm{IV}}, \mathrm{Ti}^{\mathrm{IV}}$ ) are able to intensify the processes of wood peroxide delignification in the media of organic solvents [14 - 16]. The activity of these catalysts in the processes of wood peroxide delignification is due to their ability to interact with hydrogen peroxide to form peroxocomplexes which are strong oxidants, as well their ability to generate active radicals of $\cdot \mathrm{OH}$ and $\cdot \mathrm{OOH}$, that carry out oxidative destruction of lignin.

Catalytic peroxide delignification in the medium "organic acid-water" is used for wood biomass fractionation on cellulose and soluble products from lignin and hemicelluloses [17,18]. The possibility of one-stage production of microcrystalline cellulose (MCC) with the use of a peroxide fractionation in the medium "acetic acid-water" in the presence of $1 \mathrm{wt} \% \mathrm{TiO}_{2}$ catalyst was shown [19].

Due to such properties, as nontoxicity, mechanical strength, biocompatibility, high surface area the microcrystalline cellulose finds wide application in medicine, pharmaceutical, food, cosmetic and perfumery industries, in the production of sorbents and composite materials etc. [20 - 22]. On the basis of MCC it is possible to obtain microfibrillated and nanocrystalline celluloses with unique properties [23]. 
Catalytic oxidation in a water-alkaline medium makes it possible to fractionate the wood biomass on cellulose and aromatic aldehydes [24]. Aromatic aldehydes-vanillin, syringaldehyde and para-hydroxybenzaldehyde are used in pharmaceutical, food and perfumery industries [25].

Larch wood and pine wood are the predominant coniferous species in the forests of Russia and in many other countries. Larch wood has a high density and a large amount of extractive compounds. Pine wood contains a lot of resinous substance. These features of larch wood and pine wood complicate their use in pulp and paper industry [26,27]. The most promising way of larch and pine biomass processing is to produce valuable chemicals.

In the present study the optimized processes of softwood catalytic oxidation by $\mathrm{H}_{2} \mathrm{O}_{2}$ and $\mathrm{O}_{2}$ aimed at the production of microcrystalline, microfibrillated and nanocrystalline celluloses, vanillin, organic acids and monosugars are described. The new approaches to larch wood biorefinery based on the processes of catalytic oxidation are proposed.

\section{Experimental}

\subsection{Initial wood materials}

Air dry sawdust (fraction 2-5 mm) of larch wood and pine wood harvested in the forest area near Krasnoyarsk city was used in experiments. The content of cellulose, lignin and hemicelluloses in wood was defined by analytical methods, common in wood chemistry [28]. The chemical composition of larch wood (wt $\%$ ): cellulose $-41.2 \pm 0.8$, lignin $-28.1 \pm 1.5$, hemicelluloses $-26.4 \pm 1.2$ and that of pine wood (wt\%): cellulose $-47.6 \pm 0.9$, lignin $-28.0 \pm 1.4$, hemicelluloses $-16.5 \pm 0.8$.

\subsection{Catalysts}

Soluble compounds $\mathrm{CuSO}_{4} \cdot 5 \mathrm{H}_{2} \mathrm{O}, \quad \mathrm{ZnSO}_{4} \cdot 7 \mathrm{H}_{2} \mathrm{O}, \quad \mathrm{MnSO}_{4} \cdot \mathrm{H}_{2} \mathrm{O}, \quad \mathrm{FeSO}_{4} \cdot 7 \mathrm{H}_{2} \mathrm{O}$, $\left(\mathrm{NH}_{4}\right)_{6} \mathrm{Mo}_{7} \mathrm{O}_{24}$ (all of special purity, Sigma Tech, Russia), commercial $\mathrm{TiO}_{2}$ (analytical purity, DuPont, USA), commercial KN-30 (structural form of zeolite type ZSM-5, special purity, STC"CEOSIT", Novosibirsk, Russia) and zeolite C-Fe25MS were used as catalysts in wood peroxide oxidation process. Catalyst $\mathrm{TiO}_{2}$ has a phase composition: rutile $92 \%$ and anatase $8 \%$. Zeolite catalysts C-FeZSM-5 were synthesized using the procedure, described in [29]. The sample of the catalyst was hydrothermally synthesized using silica powder, sodium hydroxide, ferric nitrate and tetrapropylammonium bromide (TPABr) as a structure-directing agent. The mixture was placed in an autoclave and kept at $150^{\circ} \mathrm{C}$ for 72 hours. The zeolite crystals are filtered off, washed with distilled water, dried and anneal at $500^{\circ} \mathrm{C}$ for 5 hours in air.

Acid-modified catalysts Sibunit and SBA-15 were used in hydrolysis of arabinogalactan. Sibunit is a mesoporous graphitized carbon [30]. Acid modification of Sibunit was implemented 
at first with 35\% $\mathrm{HNO}_{3}$ (GOST 4461-71, Russia) and then with 70\% sulfuric acid (specification 2612-005-56853252-2003, Russia) using the procedure [31].

Acid modification of SBA-15 included the fixing of 3-mercaptopropyltrimethoxysilan $\left(\mathrm{C}_{6} \mathrm{H}_{16} \mathrm{O}_{3} \mathrm{SSiAldrich}\right.$, Cat.: 175617) and further oxidation of SH-groups to sulfone groups ($\mathrm{SO}_{3} \mathrm{H}$ ) by treatment with $30 \% \mathrm{H}_{2} \mathrm{O}_{2}$ (GOST 177-88, Russia) at room temperature as in [32]. Textural characteristics of solid catalysts are given in Table 1.

Table 1 Textural characteristics and acidity of solid catalysts

\begin{tabular}{ccccccc}
\hline № & Catalyst & $\begin{array}{c}\mathrm{S} \text { BET, } \\
\mathrm{m}^{2} / \mathrm{g}\end{array}$ & $\begin{array}{c}\text { Total pore volume, } \\
\mathrm{cm}^{3} / \mathrm{g}\end{array}$ & $\begin{array}{c}\text { Pore } \\
\text { size, } \mathrm{nm}\end{array}$ & $\begin{array}{c}\mathrm{Fe} \\
\text { content, } \\
\mathrm{wt} \%\end{array}$ & $\begin{array}{c}\text { Concentration } \\
\text { of acid groups* } \\
\mathrm{mmol} / \mathrm{g}\end{array}$ \\
\hline 1 & $\mathrm{TiO}_{2}$ & near 1 & 0.01 & 6.3 & - & - \\
2 & C-FeZSM-5 & 311 & 0.18 & 2.3 & 2.82 & - \\
3 & KN-30 & 304 & 0.27 & 3.5 & 5.00 & - \\
4 & Acid-modified & 258 & 0.39 & 6.1 & & 0.13 \\
5 & $\begin{array}{c}\text { Sibunit } \\
\mathrm{SO}_{3} \text { H-SBA-15 }\end{array}$ & 495 & 0.59 & 4.7 & - & 0.41 \\
\hline
\end{tabular}

*Titration by $\mathrm{NaOH}$

The amount of catalyst in all experiments was $1 \%$ from the weight of the wood.

\subsection{Catalytic peroxide fractionation of larch wood}

Catalytic fractionation of wood sawdust by $\mathrm{H}_{2} \mathrm{O}_{2}$ was carried out using $250 \mathrm{~cm}^{3}$ glass reactor equipped with mechanical stirrer, reflux condenser and thermometer, according to the procedure described in [33]. Wood sawdust (10 g) was placed into glass reactor. Then, a mixture of glacial acetic acid (high purity, Ekos-1, Russia), hydrogen peroxide (high purity, Ekos-1, Russia), distilled water and the catalyst was added. The fraction of solid catalysts $0.2-0.5 \mathrm{~mm}$ was used in experiments. The reaction mixture was vigorously stirred $(700 \mathrm{rpm})$ at selected temperature $\left(70-100^{\circ} \mathrm{C}\right)$ during $1-4 \mathrm{~h}$. Composition of the reaction mixture was varied in the following range: hydrogen peroxide $2-6 \mathrm{wt} \%$, acetic acid $15-30 \mathrm{wt} \%$, liquid/wood ratio (LWR) 10-20. When the reaction was completed, the solid product was separated under vacuum using Buchner funnel, following by washing at distilled water and drying at $105{ }^{\circ} \mathrm{C}$ until constant weight. Such parameter as the residual lignin content in cellulose product was used to evaluate the delignification activity of catalysts.

The cellulose product yield was estimated by gravimetric method and calculated as follows: $\mathrm{Y}=\left(\mathrm{m} / \mathrm{m}_{\mathrm{o}}\right) \times 100$, where $\mathrm{Y}$ - yield of cellulose product, $\mathrm{wt} \% ; \mathrm{m}$ - weight of abs. dry cellulose product, $\mathrm{g} ; \mathrm{m}_{\mathrm{o}}-$ weight of abs. dry wood, $\mathrm{g}$.

Cellulose product was used to produce nanocelluloses by controlled acid-hydrolysis. The hydrolysis was performed by $55 \% \mathrm{H}_{2} \mathrm{SO}_{4}$ at $25{ }^{\circ} \mathrm{C}$ for $60-240$ min under vigorous mechanical stirring. The hydrolysis process was quenched by adding $150 \mathrm{ml}$ chilled distilled water followed 
by successive centrifugation at $3000 \mathrm{rpm}$ for $15 \mathrm{~min}$ to remove acidic solution. Unhydrolyzed cellulose was separated by centrifugation at $3000 \mathrm{rpm}$ for 30 minutes. The solid was frozen at $-18{ }^{\circ} \mathrm{C}$ and then dried under vacuum in a freeze dryer for 72 hours to produce of microfibrillated cellulose (MFC).

Nanocrystalline cellulose (NCC) was produced by ultrasonic treatment of MFC suspension for 15-45 $\mathrm{min}$ followed by centrifugation at $8000 \mathrm{rpm}$ for $15 \mathrm{~min}$. The MFC precipitate and the NCC suspension were refrigerated for 24 hours at $-18{ }^{\circ} \mathrm{C}$, and then dried under vacuum in a freeze drying for 72 hours.

\subsection{Catalytic fractionation of larch wood and pine wood by oxygen}

Oxidation of the wood by oxygen was performed in a stainless steel PTFE-sealed batch reactor of 1 liter capacity at $160-170{ }^{\circ} \mathrm{C}$ and at the oxygen partial pressure $0.2-$ $0.3 \mathrm{MPa}(\mathrm{g})$, using the procedure, described in [34]. A reaction mixture was prepared by sequentially adding the desired amounts of distilled water, wood sawdust, aqueous solutions, $\mathrm{NaOH}$ and catalyst $\left(\mathrm{CuSO}_{4} \cdot 5 \mathrm{H}_{2} \mathrm{O}\right)$, all while stirring. The reactor was flushed by argon and heated to the desired temperature at the rate of $3-8{ }^{\circ} \mathrm{C} / \mathrm{min}$. After the certain reaction duration, the reaction mixture was filtered. The solid rest was mixed with $500 \mathrm{ml}$ of distilled water; the mixture was acidified to $\mathrm{pH} 2$ by $32 \mathrm{wt} \% \mathrm{HCl}$ in order to dissolve the copper oxide. After filtering, the resulting solid cellulose was dried until a constant weight. Vanillin was extracted from the solution by chloroform. The vanillin content in the extract was determined by GC.

\subsection{Catalytic hydrolysis of arabinogalactan}

Hydrolysis of arabinogalactan (AG) in the presence of sulfuric acid catalyst was carried out in a glass reactor at temperature $100{ }^{\circ} \mathrm{C}$. $\mathrm{AG}(0.75 \mathrm{~g})$ was placed into reactor, and then 150 $\mathrm{ml}$ of solution of $0.1 \mathrm{M} \mathrm{H}_{2} \mathrm{SO}_{4}$ was added. The reaction mixture was stirred ( $840 \mathrm{rpm}$ ) during 1$7 \mathrm{~h}$ and the obtained hydrolyzate was analyzed by GC.

Hydrolysis of AG in the presence of solid acid catalysts (fraction $0.2-0.5 \mathrm{~mm}$ ) was studied at temperatures of $100-150{ }^{\circ} \mathrm{C}$ in a rotating steel autoclave with $35 \mathrm{ml}$ fluoroplastic tube. AG $(0.075 \mathrm{~g})$ and solid catalyst $(0.075 \mathrm{~g})$ were placed into the tube, and then $15 \mathrm{ml}$ of distilled water was added. Hydrolysis time was varied from 60 to $420 \mathrm{~min}$ with autoclave rotation speed $14 \mathrm{rpm}$. When reaction was completed, the catalyst was separated under vacuum using Bucher funnel and the obtained hydrolyzate was analyzed by GC.

\subsection{Chemical analysis}

The content of cellulose, hemicelluloses and lignin in the initial wood and in the cellulose products was defined by chemical methods generally accepted in wood chemistry [28]. 
The cellulose was determined gravimetrically according to Kürschner and Hoffer method [28]. The hemicelluloses were calculated as the difference between the weights of holocellulose and cellulose. The holocellulose was determined by gravimetric method [35]. Acid-insoluble lignin (Klasson lignin) was determined according to TAPPI [36].

Three replicates were used for each experiments and the deviations are given in Tables

\subsection{Determination of the degree of polymerization of cellulose}

The degree of cellulose polymerization was calculated according to ASTM 1795 [37].

Degree of polymerization of cellulose was calculated according to equation [38]:

$$
\mathrm{DP}^{0.905}=0.805 \times[\eta]
$$

where DP degree of polymerization; $[\eta]$ intrinsic viscosity.

\subsection{Infrared spectroscopy analysis (FTIR)}

FTIR spectra were recorded with Bruker Tensor -27 in the range of wavelength 4000 $400 \mathrm{~cm}^{-1}$. Samples for analysis (4 mg for each) were prepared in tablets with matrix $\mathrm{KBr}$. Spectral data were processed by the program OPUS/YR (version 2.2).

\section{9. $X$-ray diffraction analysis $(X R D)$}

XRD analysis was carried out on PANalytical X'Pert Pro diffractometer using $\mathrm{Cu}-\mathrm{Ka}$ source $(A=0.154 \mathrm{~nm})$ in the $2 \theta$ range $5-70^{\circ}$ and scanning step width of $0.01 \%$ scan. The samples were analyzed by the powder method in cuvette with $2.5 \mathrm{~cm}$ diameter. Crystallinity index (CI) was calculated from the ratio of the height between the intensity of the crystalline peak and total intensity after subtraction of the background signal [39].

\subsection{Nitrogen adsorption measurements (BET)}

The specific surface areas and pore volumes of the samples were determined using BET method. Nitrogen adsorption - desorption isotherms were obtained at $77 \mathrm{~K}$ on a Micromeritics ASAP 2020 analyzer.

\subsection{Scanning electron microscopy (SEM) study}

The electron images were obtained by scanning electron microscopy (SEM) TM-1000 HITACHI (Japan) with acceleration potentional $15 \mathrm{kV}$. Samples were coated on carbon support.

\subsection{Atomic force microscopy (AFM) study}

AFM images were obtained with the scanning probing multimode microscope Solver P47 (NT-MDT, Moscow). Transparent films of samples were prepared by evaporation of their water solutions on a flat support made of glass. The rate of scanning was 40-55 $\mu \mathrm{m} / \mathrm{s}$, and the number of points on the scanning area was $256 \times 256$ or $512 \times 512$.

\subsection{Gel permeation chromatography (GPC) analysis}

Molecular weight of lignins was examined using a gel permeation chromatograph (“Agilent Technologies@1260 Infinity, U.S.) with a refractive index detector, using an Agilent 
PLgel Mixed-C column. Chloroform was used as the eluent, with a flow rate of $1.0 \mathrm{ml} / \mathrm{min}$ at 40 ${ }^{\circ} \mathrm{C}$. Typical sample volumes were $50 \mathrm{ml}$ at a polymer concentration of $2 \mathrm{mg} / \mathrm{ml}$. Narrow polydispersity polystyrene standards (Agilent, U.S.) were used to generate a universal calibration curve, from which molecular weights (weight average, Mw, and number average, Mn) and polydispersity were determined.

\subsection{Solid state ${ }^{13}$ C CP-MAS NMR spectroscopy study}

Solid state ${ }^{13} \mathrm{C}$ CP-MAS NMR spectra of cellulose was recorded with the use of Bruker Avance III spectrometer, operating at $150.9 \mathrm{MHz}{ }^{13} \mathrm{C}$ resonance frequency. Sample was packed in $3.2 \mathrm{~mm}$ rotors and spun at $7.5 \mathrm{kHz}$. The spectrum was acquired at $25{ }^{\circ} \mathrm{C}$. Acquisition parameters were set as follows: acquisition time $0.33 \mathrm{~ms}$, cross-polarization contact time $3 \mathrm{~ms}$, 4096 accumulated scans with repetition interval 5 s. Chemical shifts were referenced relative to adamantane as external standard (methylene at $\delta^{13} \mathrm{C}=29.5 \mathrm{ppm}$ ). The acquired free induction decays were multiplied with exponential window function with $25 \mathrm{~Hz}$ line broadening before Fourier transformation.

\subsection{Gas chromatography mass spectrometry (GC-MS) analysis}

The liquid products of wood peroxide delignification were analyzed by GC-MS using Agilent 7890A chromatograph fitted with an Agilent 7000A Triple Quad mass-selective detector (Agilent, United States) by recording the total ion current. The products were separated in an HP-5MS capillary column $(30 \mathrm{~m}$ in length, $0.25 \mathrm{~mm}$ in inner diameter) in the temperature programmed mode while raising the temperature from 40 to $250{ }^{\circ} \mathrm{C}$ at a rate of $3{ }^{\circ} \mathrm{C} / \mathrm{min}$.

\subsection{Gas chromatography analysis}

The vanillin and monosaccharides contents were determined using a gas chromatograph "VARIAN-450 GC' with a flame ionization detector and a capillary column VF-624 ms with $30 \mathrm{~m}$ length and inner diameter $0.32 \mathrm{~mm}$.

\subsection{High performance liquid chromatography (HPLC) analysis}

Levulinic acid content was determined by HPLC method using chromatograph "Milichrom A-02" (Econova, Novosibirsk) with scanning spectrophotometric detector UV range190-360 $\mathrm{nm}$. Column made of stainless steel $(2.0 \times 75 \mathrm{~mm})$ and packed with silica gel Pronto SIL-120-5-C18 AQ with a grain size of $5.0 \mu \mathrm{m}$ was used.

Standards of analytical grade were used: glucose (Panreac, Germany), D (+)-mannose, (Panreac, Germany), D (+) Xylose (Panreac, Germany), L(+) Arabinosa (Panreac, Germany), $\mathrm{D}(+)$ Galactose (Panreac, Germany), D-sorbitol (Panreac, Germany) and levulinic acid (SigmaAldrich, USA). 


\section{Results and discussion}

\subsection{Production of chemicals by catalytic peroxide fractionation of larch wood}

\subsubsection{Effect of the catalyst nature}

Catalytic properties of soluble $\left(\mathrm{CuSO}_{4}, \mathrm{ZnSO}_{4}, \mathrm{MnSO}_{4}, \mathrm{FeSO}_{4},\left(\mathrm{NH}_{4}\right)_{6} \mathrm{Mo}_{7} \mathrm{O}_{24}\right)$ and solid $\left(\mathrm{TiO}_{2}\right.$, zeolites $\mathrm{KN}-30$ и C-FeZSM-5) catalysts were compared in the process of larch wood peroxide oxidation in the medium «acetic acid-water». The process conditions (temperature 90 ${ }^{\circ} \mathrm{C}$, concentration of $\mathrm{H}_{2} \mathrm{O}_{2} 6 \mathrm{wt} \%, \mathrm{CH}_{3} \mathrm{COOH} 30 \mathrm{wt} \%$, liquid/wood ratio (LWR) 15, duration 4 h) were selected based on our recent study [40].

The content of residual lignin in cellulose products was used to evaluate the delignification ability of catalysts.

Zeolite catalysts C-FeZSM-5 and $\mathrm{KN}-30$, as well as $\mathrm{FeSO}_{4}$ and $\mathrm{CuSO}_{4}$ promote the intensive decomposition of $\mathrm{H}_{2} \mathrm{O}_{2}$ and they have low ability in wood delignification. The catalyst $\left(\mathrm{NH}_{4}\right)_{6} \mathrm{Mo}_{7} \mathrm{O}_{24}$ has the highest delignification ability (Fig. 1 and Table 2).

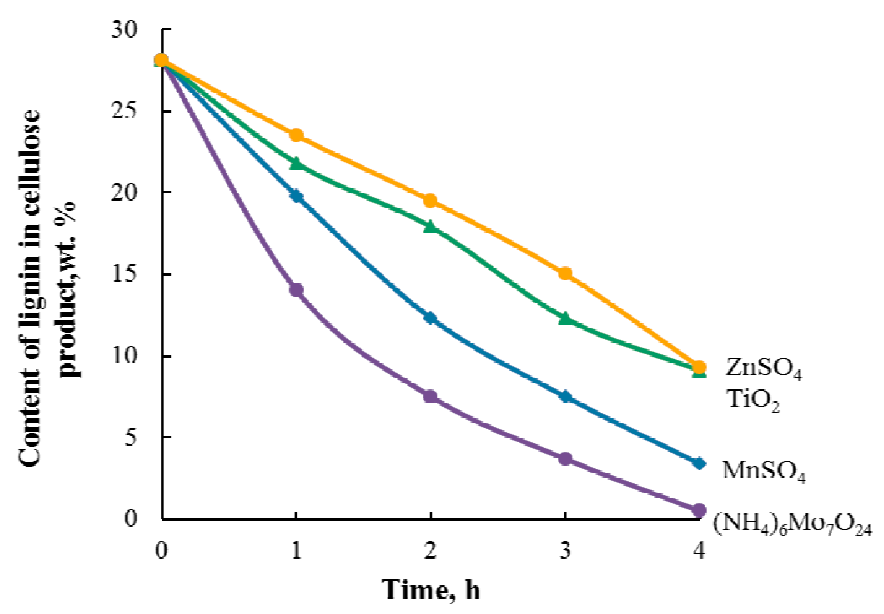

Fig.1 Dynamics of changes of the residual lignin content in larch wood during peroxide delignification in the acetic acid-water medium $\left(90{ }^{\circ} \mathrm{C}, \mathrm{H}_{2} \mathrm{O}_{2} 6 \mathrm{wt} \%, \mathrm{CH}_{3} \mathrm{COOH} 30 \mathrm{wt} \%\right.$, catalyst $1 \mathrm{wt} \%$, LWR 15)

\section{Table 2}

Yield and composition of cellulose products obtained by catalytic peroxide delignification of larch wood (temperature $90{ }^{\circ} \mathrm{C}$, concentrations of $\mathrm{H}_{2} \mathrm{O}_{2} 6 \mathrm{wt} \%, \mathrm{CH}_{3} \mathrm{COOH} 30 \mathrm{wt} \%$, catalyst 1 wt $\%$, LWR 15, time 4 h)

\begin{tabular}{cccccc}
\hline \multirow{2}{*}{ № } & \multirow{2}{*}{ Catalyst } & $\begin{array}{c}\text { Yield of cellulose } \\
\text { product, wt } \%\end{array}$ & \multicolumn{3}{c}{ Composition of cellulose product, wt\% } \\
\cline { 3 - 6 } & & $43.7 \pm 1.2$ & $91.7 \pm 0.7$ & $1.2 \pm 0.1$ & Cellulose \\
\hline 1 & $\left(\mathrm{NH}_{4}\right)_{6} \mathrm{Mo}_{7} \mathrm{O}_{24}$ & $45.0 \pm 1.2$ & $88.9 \pm 0.8$ & $3.9 \pm 0.2$ & $6.9 \pm 0.3$ \\
2 & $\mathrm{MnSO}_{4}$ & $54.8 \pm 1.3$ & $73.3 \pm 1.0$ & $21.0 \pm 1.5$ & $5.4 \pm 0.2$ \\
3 & $\mathrm{FeSO}_{4}$ & $45.9 \pm 1.1$ & $87.4 \pm 1.0$ & $9.7 \pm 0.3$ & $5.6 \pm 0.2$ \\
4 & $\mathrm{ZnSO}_{4}$ & $54.6 \pm 1.4$ & $73.3 \pm 1.1$ & $24.3 \pm 1.5$ & $2.1 \pm 0.2$ \\
5 & $\mathrm{CuSO}_{4}$ & $47.3 \pm 1.3$ & $84.1 \pm 0.9$ & $9.5 \pm 0.3$ & $5.9 \pm 0.3$ \\
6 & $\mathrm{TiO}_{2}$ & $56.0 \pm 1.5$ & $71.5 \pm 0.9$ & $20.1 \pm 1.4$ & $8.1 \pm 0.4$ \\
7 & $\mathrm{C}-\mathrm{FeZSM}-5$ & $57.8 \pm 1.4$ & $69.3 \pm 1.0$ & $24.2 \pm 1.4$ & $6.2 \pm 0.3$ \\
8 & $\mathrm{KN}-30$ & & & & Hemicelluloses \\
\hline
\end{tabular}


The delignification ability of catalysts at temperature $90{ }^{\circ} \mathrm{C}$ decreases in the following sequence (Table 2):

$\left(\mathrm{NH}_{4}\right)_{6} \mathrm{Mo}_{7} \mathrm{O}_{24}>\mathrm{MnSO}_{4}>\mathrm{ZnSO}_{4}>\mathrm{TiO}_{2}>>\mathrm{C}-\mathrm{FeZSM}-5 \sim \mathrm{KN}-30 \sim \mathrm{FeSO}_{4} \sim \mathrm{CuSO}_{4}$.

The processes of larch wood catalytic peroxide delignification at $90{ }^{\circ} \mathrm{C}$ are described by the first order equations. The rate constants of lignin removal from wood during peroxide delignification in the presence of different catalysts are given in table 3.

The rate constants of wood peroxide delignification process are varied between $1.92 \cdot 10^{-4}$ and $0.59 \cdot 10^{-4}$, depending on the catalyst nature.

\section{Table 3}

Rate constants of lignin removal from larch wood during catalytic peroxide delignification at temperature $90{ }^{\circ} \mathrm{C}\left(\mathrm{H}_{2} \mathrm{O}_{2} 6 \mathrm{wt} \%, \mathrm{CH}_{3} \mathrm{COOH} 30 \mathrm{wt} \%\right.$, catalyst $1 \mathrm{wt} \%$, LWR 15).

\begin{tabular}{ccc}
\hline № & Catalyst & $\mathrm{k}, \mathrm{s}^{-1}$ \\
\hline 1 & $\left(\mathrm{NH}_{4}\right)_{6} \mathrm{Mo}_{7} \mathrm{O}_{24}$ & $1.92 \cdot 10^{-4}$ \\
2 & $\mathrm{MnSO}_{4}$ & $1.28 \cdot 10^{-4}$ \\
3 & $\mathrm{TiO}_{2}$ & $0.68 \cdot 10^{-4}$ \\
4 & $\mathrm{ZnSO}_{4}$ & $0.59 \cdot 10^{-4}$ \\
\hline
\end{tabular}

The most active molybdenum catalyst was used in the process of larch wood fractionation to produce of microcrystalline, microfibrillated, nanocrystalline celluloses and low molecular weight organic compounds.

\subsubsection{Production of microcrystalline cellulose}

Industrial processes of cellulose production are carried out at elevated temperatures (125$\left.175^{\circ} \mathrm{C}\right)$ and pressures $(0.7-1.2 \mathrm{MPa})$ and they use the environmentally hazardous sulfur- and chlorine-containing reagents [41].

In this study the microcrystalline cellulose was produced by peroxide delignification of larch wood at temperatures $70-100{ }^{\circ} \mathrm{C}$ with the use of environmentally friendly reagents: water, hydrogen peroxide, acetic acid. The soluble catalyst $\left(\mathrm{NH}_{4}\right)_{6} \mathrm{Mo}_{7} \mathrm{O}_{24}$ was used to intensify the process of lignin removal from wood.

The influence of conditions of larch wood catalytic peroxide oxidation on the yield and composition of cellulose products was studied. It was found that the temperature of the process of wood oxidation influences on the yield of cellulose product and on the content of residual lignin and cellulose (Table 4). 


\section{Table 4}

Effect of the temperature on the yield and composition of cellulose product obtained by catalytic peroxide delignification of larch wood $\left(\mathrm{CH}_{3} \mathrm{COOH} 30 \mathrm{wt} \%, \mathrm{H}_{2} \mathrm{O}_{2} 6 \mathrm{wt} \%\right.$, time $4 \mathrm{~h}$, LWR 15)

\begin{tabular}{ccccc}
\hline \multirow{2}{*}{$\begin{array}{c}\text { Temperature } \\
{ }^{\circ} \mathrm{C}\end{array}$} & $\begin{array}{c}\text { Yield of } \\
\text { cellulose } \\
\text { product, wt } \% *\end{array}$ & Cellulose & Lignin & Hemicelluloses \\
\cline { 3 - 5 } & $59.2 \pm 1.4$ & $67.8 \pm 0.8$ & $23.9 \pm 1.5$ & $7.3 \pm 0.5$ \\
80 & $53.6 \pm 1.3$ & $74.9 \pm 0.8$ & $17.8 \pm 1.4$ & $6.3 \pm 0.4$ \\
90 & $43.7 \pm 1.2$ & $91.7 \pm 0.7$ & $1.2 \pm 0.1$ & $6.1 \pm 0.3$ \\
100 & $40.0 \pm 1.3$ & $93.7 \pm 0.5$ & $0.3 \pm 0.1$ & $5.0 \pm 0.3$ \\
\hline
\end{tabular}

* on abs. dry wood. ** on abs. dry cellulose product.

Under the conditions tested the effective removal of lignin from wood occurs at temperature $90{ }^{\circ} \mathrm{C}$ and the produced cellulose contains $1.2 \pm 0.1 \mathrm{wt} \%$ of residual lignin. Cellulose produced at temperature of $100{ }^{\circ} \mathrm{C}$ practically does not contain residual lignin (Table 4). The yield of cellulose product reduces to $40.0 \pm 1.3 \mathrm{wt} \%$ when the temperature of peroxide oxidation increases from $70{ }^{\circ} \mathrm{C}$ to $100{ }^{\circ} \mathrm{C}$.

The value of liquid to wood ratio (LWR) also influences on the cellulose product yield and composition. The increase of LWR reduces the contribution of diffusion limitation in the process of wood peroxide delignification. However, the use of high values of LWR is not economically feasible. Earlier we found that the peroxide delignification of larch sawdust at temperature range $70-100{ }^{\circ} \mathrm{C}$ proceeds in the kinetic region at LWR equal to 15 [40]. This value of LWR was used in the study of the features of larch wood peroxide oxidation in "acetic acidwater" medium in the presence of catalyst $\left(\mathrm{NH}_{4}\right)_{6} \mathrm{Mo}_{7} \mathrm{O}_{24}$. The data in the Table 5 show the effect of the reaction mixture composition on the yield and composition of cellulose products obtained from larch wood.

\section{Table 5}

Effect of the concentration of $\mathrm{H}_{2} \mathrm{O}_{2}$ and $\mathrm{CH}_{3} \mathrm{COOH}$ on the yield and composition of cellulose product obtained by catalytic peroxide delignification of larch wood $\left(100{ }^{\circ} \mathrm{C}, 4 \mathrm{~h}, \mathrm{LWR} 15\right)$

\begin{tabular}{|c|c|c|c|c|c|c|c|c|}
\hline \multirow{2}{*}{ Parameters } & \multicolumn{4}{|c|}{$\mathrm{H}_{2} \mathrm{O}_{2}$ concentration, wt $\%$} & \multicolumn{4}{|c|}{$\mathrm{CH}_{3} \mathrm{COOH}$ concentration, wt $\%$} \\
\hline & 2 & 4 & 5 & 6 & 15 & 20 & 25 & 30 \\
\hline $\begin{array}{l}\text { Yield of cellulose } \\
\text { product, wt \%* }\end{array}$ & $47.0 \pm 1.3$ & $44.8 \pm 1.2$ & $41.7 \pm 1.2$ & $40.0 \pm 1.3$ & $43.9 \pm 1.4$ & $43.5 \pm 1.2$ & $42.2 \pm 1.3$ & $40.0 \pm 1.3$ \\
\hline $\begin{array}{l}\text { Product } \\
\text { composition, wt\% } \\
* *: \\
\text { Cellulose }\end{array}$ & $87.5 \pm 0.8$ & $92.5 \pm 1.0$ & $93.7 \pm 0.7$ & $93.7 \pm 0.5$ & $92.0 \pm 0.9$ & $92.2 \pm 0.9$ & $92.9 \pm 0.8$ & $93.7 \pm 0.5$ \\
\hline lignin & $5.2 \pm 0.2$ & $0.6 \pm 0.1$ & $0.2 \pm 0.1$ & $0.3 \pm 0.1$ & $1.1 \pm 0.2$ & $1.0 \pm 0.2$ & $0.8 \pm 0.1$ & $0.3 \pm 0.1$ \\
\hline hemicelluloses & $6.3 \pm 0.3$ & $5.9 \pm 0.3$ & $5.1 \pm 0.2$ & $5.0 \pm 0.3$ & $5.9 \pm 0.2$ & $5.8 \pm 0.2$ & $5.3 \pm 0.3$ & $5.0 \pm 0.3$ \\
\hline
\end{tabular}

* on abs. dry wood. ** on abs. dry cellulose product. 
The increase in the concentration of $\mathrm{H}_{2} \mathrm{O}_{2}$ and $\mathrm{CH}_{3} \mathrm{COOH}$ reduces the yield and the content of lignin and hemicelluloses in the cellulose product.

The optimal conditions of peroxide delignification of larch wood, providing the high yield of cellulose product $(41.7 \pm 1.2 \mathrm{wt} \%)$ with low content of residual lignin $(0.2 \pm 0.1 \mathrm{wt} \%)$ were defined, namely: temperature $100{ }^{\circ} \mathrm{C}$, concentrations of $\mathrm{H}_{2} \mathrm{O}_{2} 5 \mathrm{wt} \%, \mathrm{CH}_{3} \mathrm{COOH} 30 \mathrm{wt} \%$, catalyst $\left(\mathrm{NH}_{4}\right)_{6} \mathrm{Mo}_{7} \mathrm{O}_{24} 1 \mathrm{wt} \%$, value LWR 15, time $4 \mathrm{~h}$. Cellulose, produced at these conditions has the following chemical composition (wt\%): cellulose 93.7 \pm 0.7 , lignin $0.2 \pm 0.1$, hemicelluloses 5.1 \pm 0.2 . According to FTIR and XRD and solid state ${ }^{13} \mathrm{C} \mathrm{CP} / \mathrm{MAS}$ NMR data the structure of this cellulose is similar to microcrystalline cellulose (MCC).

In FTIR spectrum the absorption peak at $1430 \mathrm{~cm}^{-1}$ corresponds to the $\mathrm{CH}_{2}$ bending vibration that is attributed to the "crystallinity band" in the cellulose [42]. The band at $893 \mathrm{~cm}^{-1}$ was attributed to the $\mathrm{C}-\mathrm{O}-\mathrm{C}$ stretching vibration of $\beta$ - $(1 \rightarrow 4)$-glycoside linkages of cellulose, which was considered as an "amorphous band" in the cellulose [42]. The ratio of peak areas 1430/893 was proposed as similar to cellulose type I crystallinity [43]. Practically, the same values of this ratio for cellulose from larch wood (1.13) and for commercial MCC (1.12) indicate the similar structures for both samples.

According to XRD diffraction data, the cellulose from larch wood and the commercial MCC have a crystal lattice typical for cellulose I [44] and the crystallinity indexes 0.70 and 0.75 respectively (Fig. 2).

Solid state spectrum ${ }^{13} \mathrm{C}$ CP-MAS NMR has resonance lines which indicate the presence of crystalline and amorphous forms of cellulose (Fig. 2). Peaks have been assigned based on the literature data $[45,46]$ and are displayed in the Table 6.

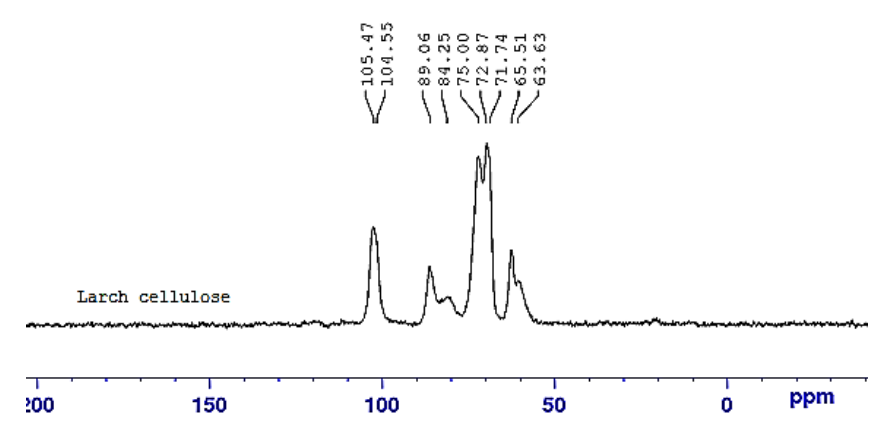

Fig.2 Solid state ${ }^{13} \mathrm{C}$ CP-MAS NMR spectrum of cellulose obtained from larch wood
Table 6. Signal assignments for ${ }^{13} \mathrm{C}$ CP-MAS NMR spectrum of cellulose obtained by catalytic peroxide oxidation of spruce wood

\begin{tabular}{cc}
\hline $\begin{array}{c}\text { Chemical } \\
\text { shift (ppm) }\end{array}$ & Assignment \\
\hline 104.9 & C-1 of cellulose \\
89.1 & C-4 of crystalline cellulose \\
84.1 & C-4 of amorphous cellulose \\
$72-75$ & C-2/C-3/C-5 of cellulose \\
65.6 & C-6 of crystalline cellulose \\
62.7 & C-6 of amorphous cellulose \\
\hline
\end{tabular}

In the process of larch wood peroxide oxidation the soluble catalyst $\left(\mathrm{NH}_{4}\right)_{6} \mathrm{Mo}_{7} \mathrm{O}_{24}$ is separated from solid cellulose product by filtration and subsequent deposition from solution with organic solvents (ethyl alcohol or acetone). 


\subsubsection{Production of microfibrillated and nanocrystalline celluloses}

We proposed to use the process of peroxide catalytic oxidation for production of microfibrillated cellulose (MFC) and nanocrystalline cellulose (NCC) from larch wood. Based on the literature data [47 - 49], the hydrolysis of MCC from larch wood by $55 \mathrm{wt} \% \mathrm{H}_{2} \mathrm{SO}_{4}$ at temperature $25{ }^{\circ} \mathrm{C}$ during 1-4 hours and the following ultrasonic treatment during 15-45 min were used to produce MFC and NCC.

Acid hydrolysis removes the amorphous part of cellulose without affecting the crystalline part, which is more stable in an acidic medium. During acid hydrolysis of cellulose, the degree of its polymerization decreases sharply and the, so-called, limit degree of polymerization can be achieved. The limit degree of polymerization corresponds to the size of crystallites along the longitudinal direction of cellulose chains in the initial cellulose [50]. Concentrated $\mathrm{H}_{2} \mathrm{SO}_{4}$ can hydrolyze at moderate temperatures not only amorphous part but to destruct strong lateral connections between crystals in cellulose microfibrils. This leads to a further decrease in the degree of polymerization of cellulose and contributes to the formation of nanosize particles (nanocrystalline cellulose) during ultrasonic treatment of microfibrillated cellulose in water medium.

Figure 3 demonstrates the changes in degree of MCC polymerization during the acid hydrolysis and ultrasonic treatment.
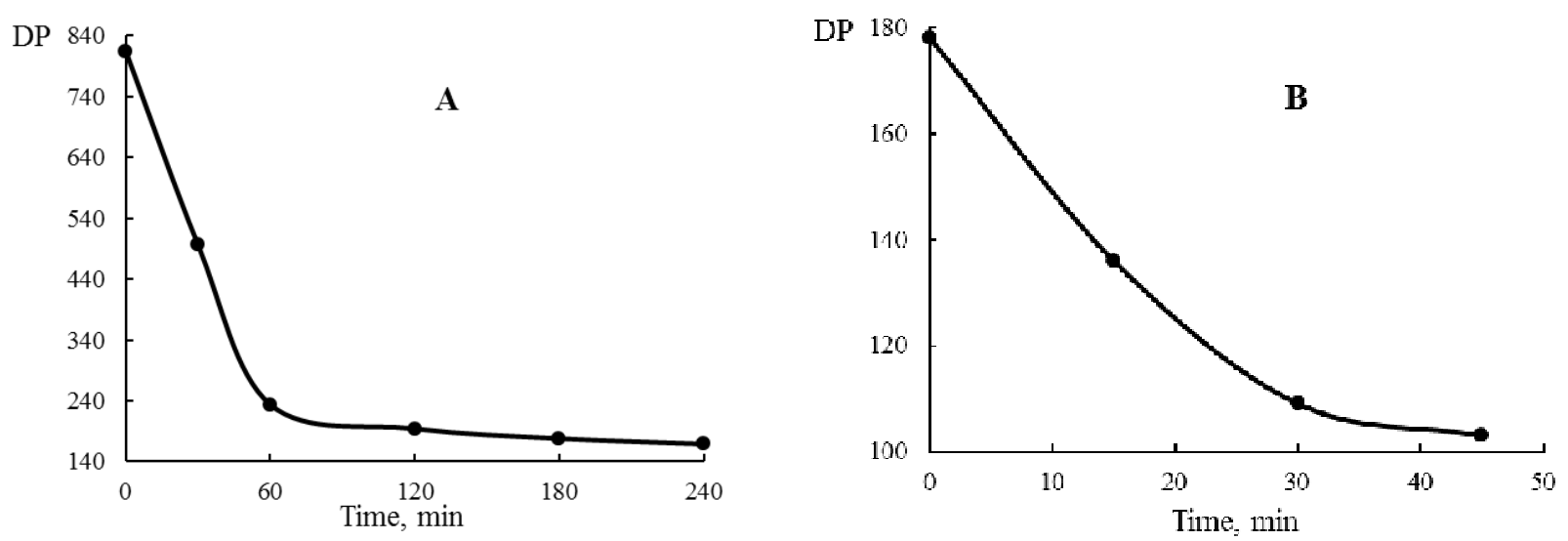

Fig. 3. Dynamics of changes in degree of polymerization during the acid-catalyzed hydrolysis of MCC (A) and ultrasonic treatment of MFC (B)

The sulfuric acid hydrolysis of MCC during $60 \mathrm{~min}$ decreases the degree of cellulose polymerization from 840 to 240. Microfibrillated cellulose (MFC) obtained by MCC hydrolysis within $240 \mathrm{~min}$ has the degree of polymerization 178 (Fig. 2A). The following ultrasonic treatment of MFC for 30 min leads to the formation of nanocrystalline cellulose (NCC) with a degree of polymerization of 109. The further increase in the duration of ultrasonic treatment up to 45 min only slightly reduces a degree of polymerization of NCC (Fig. 2 B). 
The yield of MFC after acid hydrolysis is $18.2 \mathrm{wt} \%$ and the yield of NCC after ultrasonic treatment during $30 \mathrm{~min}$ reaches $8.9 \mathrm{wt} \%$ (regarding cellulose content in larch wood). These yields are comparable to the data given in the literature $[51,52]$. So, the yields of NCC from oil palm fibers, corn stalks and MCC are $2.3 \mathrm{wt} \%, 6.0 \mathrm{wt} \%$ and $25.5 \mathrm{wt} \%$ respectively [51]. The authors of [52] point to a wide range of NCC yield values (from $3.8 \mathrm{wt} \%$ to $27.9 \mathrm{wt} \%$ ) depending on the nature of lignocellulose materials, type of preliminary treatment, conditions of acid hydrolysis and methods of nanocrystalline cellulose isolation.

Samples of MCC, MFC and NCC, produced from larch wood were characterized by FTIR, XRD, SEM, AFM and BET methods. FTIR spectra of all cellulose samples are similar. They have no absorption bands in the regions of 1605-1593, 1515-1495 and 1470-1460 $\mathrm{cm}^{-1}$ related to lignin phenylpropane units [53]. This points on the lack of noticeable amount of lignin in cellulose samples. Absorption bands in the region $1700-1740 \mathrm{~cm}^{-1}$ related to acetyl and uronic groups [54] point on the presence of residual hemicelluloses in cellulose samples.

Acid hydrolysis and ultrasonic treatment contribute to the breaking of hydrogen bonds that leads to the formation of nanofibrillated cellulose, which can be observed by scanning electron microscopy (Fig. 4).

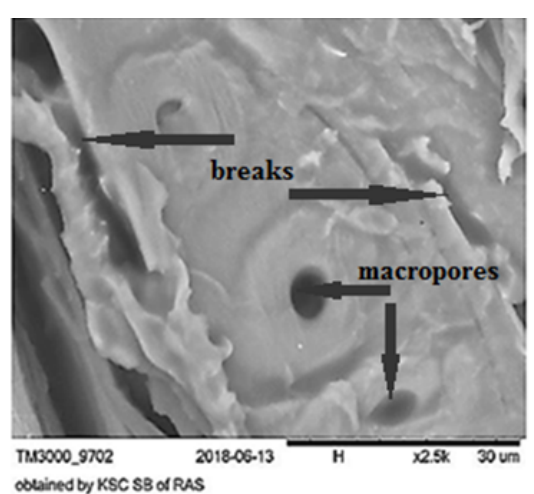

A

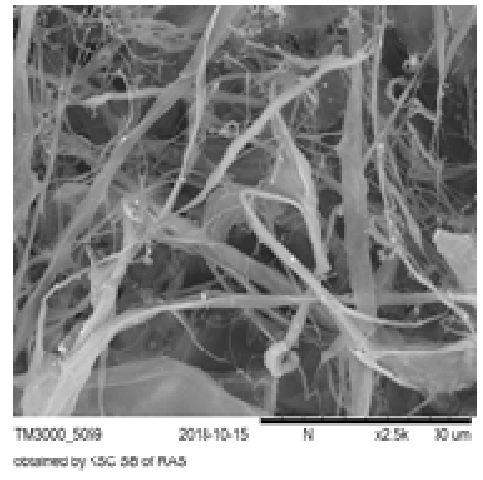

B

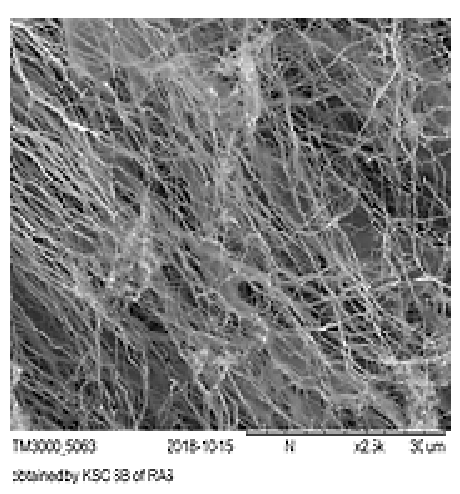

C

Fig. 4. Scanning electron microscopy images of the cellulose samples from larch wood: MCC (A), MFC (B), NCC (C). Magnification 2500 times

MCC produced by catalytic peroxide oxidation of larch wood consists of loose fibers with many breaks and macropores (Fig. 4A). The latter are probably formed as a result of removal hemicelluloses and lignin during peroxide oxidation of wood. The size of MCC particles is varied in wide limits (from 30 to $300 \mu \mathrm{m}$ ).

The porous structure of MCC facilitates a diffusion of $\mathrm{H}_{2} \mathrm{SO}_{4}$ molecules into the cellulose during the catalytic hydrolysis process. The amorphous regions of cellulose are subjected to hydrolysis and the microfibrillated cellulose is formed. MFC fibrils are quite large and have a rough surface (Fig. 4B). Subsequent ultrasonic treatment of microfibrillated cellulose results in 
the formation of nanocrystalline cellulose, consisting of smooth fibrils of smaller sizes and more uniform distribution compared to MFC (Fig. 4C).

The morphology of a surface of MFC and NCC films, obtained by evaporation of water from their water suspensions was studied by AFM method (Fig. 5).
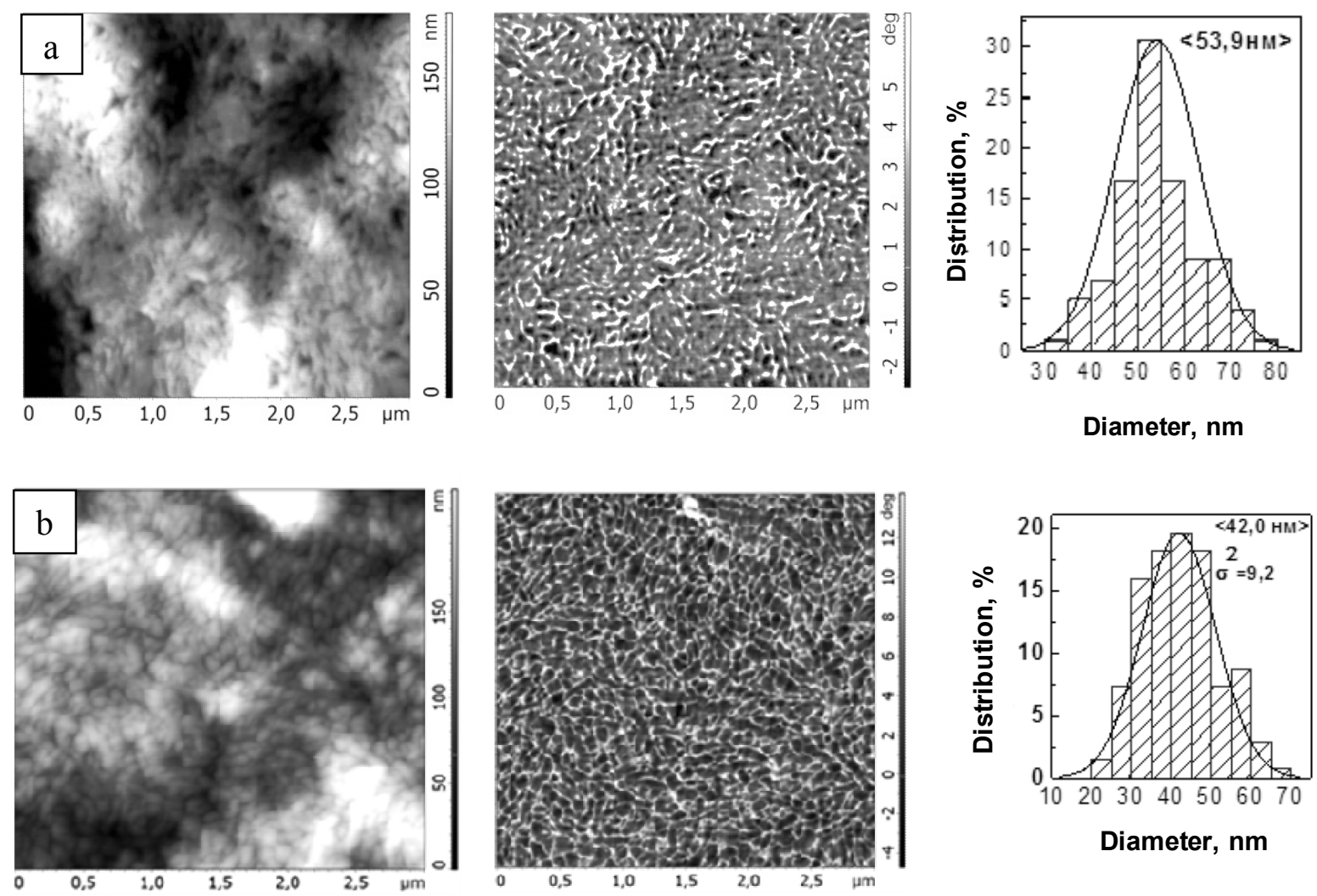

A

B

$\mathrm{C}$

Fig. 5. AFM images of the surface of MFC (a) and NCC (b) films in the relief mode (A) and in the phase contras mode (B). C - Histograms of particle size distribution.

Analysis of AFM images obtained in the relief mode and in phase contrast mode shows that the MFC film is formed by homogeneous rod-like particles with an average size $53.9 \mathrm{~nm}$ (Fig. 5A). The surface of NCC film consists of evenly packed fine particles with the average size $42 \mathrm{~nm}$ (Fig. 5B). The images obtained in the phase contrast mode point on homogeneous composition both MFC and NCC surfaces.

X-ray diffraction patterns of MCC, MFC and NCC samples are shown on Fig. 6. They have maxima at the angles $2 \theta: 15.2^{\circ}, 16^{\circ}$ and $22.6^{\circ}$ related to reflection from planes 110,101 , 002 of crystal lattice of cellulose I [39]. 


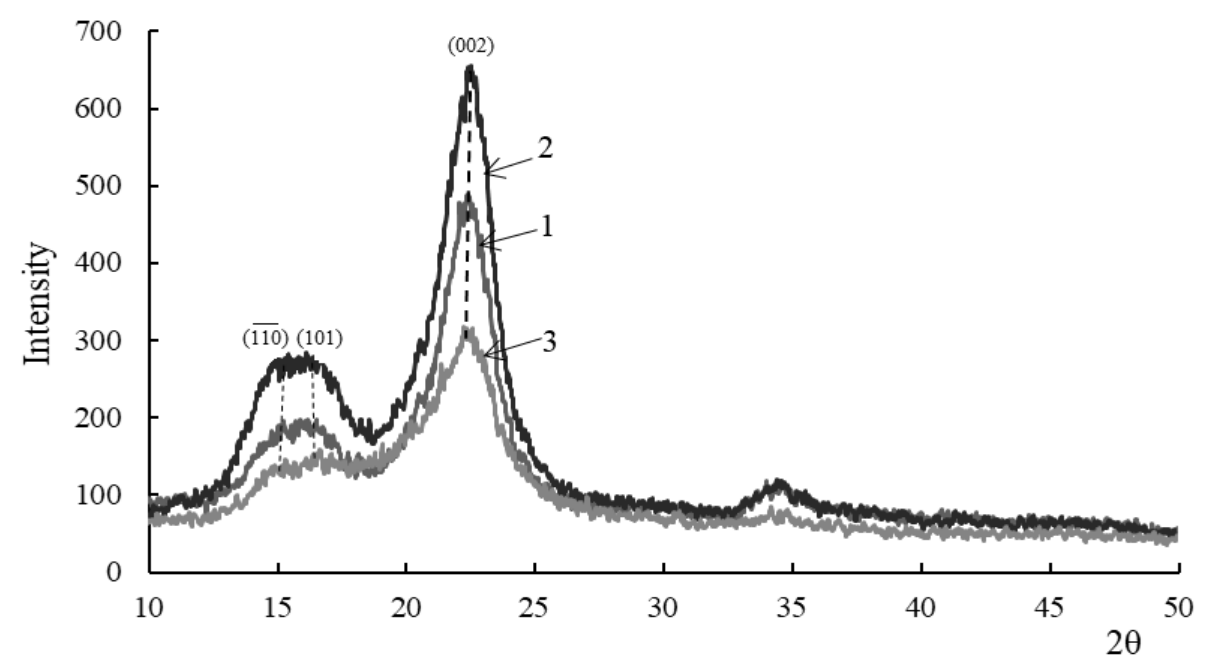

Fig. 6. X-ray diffraction patterns of the cellulose samples: 1 - MCC; 2 - MFC; 3 - NCC.

The acid-catalyzed hydrolysis of MCC to MFC and subsequent ultrasonic treatment of MFC contribute to the removal of amorphous area which is accompanied by reduction the intensity of maxima at the angles $2 \theta: 15.2-16.0^{\circ}$ and $22.6^{\circ}$ on X-ray diffraction patterns of MFC and NCC samples (Fig. 6, curves 2 and 3).

Sample of MCC produced by catalytic peroxide delignification of larch wood at optimal process conditions has a high crystallinity index $(0.70)$ due to the effective removal of lignin, hemicelluloses and amorphous cellulose from wood. When MFC is obtained by acid hydrolysis of MCC the degree of polymerization reduces from 815 to 178 and the crystallinity index increases from 0.70 to 0.78 . Similar effects in the preparation of nanocelluloses by acid hydrolysis were observed in $[55,56]$.

When NCC is obtained by ultrasonic treatment of MFC the reduction of degree of polymerization to 109 and of index crystallinity to 0.69 was observed. According to literature data [55], hydrodynamic forces arising in the aqueous medium when exposed to ultrasound have a strong mechanical effect on the crystal domains of nanocellulose, which reduce the degree of its crystallinity. For example, the ultrasonic treatment of nanocellulose from corn husk reduces the index of crystallinity from 0.83 to 0.53 [57]. Nanocellulose with crystallinity index 0.33 was obtained by ultrasonic treatment of bleached Kraft cellulose of eucalyptus with initial crystallinity index 0.69 [58].

Some characteristics of the sample of MCC, MFC and NCC, produced from larch wood are given in Table 7 . 


\section{Table 7}

Textural characteristics and the degree of polymerization (DP) of the cellulose samples produced from larch wood (CI-crystallinity index, $\mathrm{L}_{002}$-crystallite size).

\begin{tabular}{cccccc}
\hline Cellulose samples & $\begin{array}{c}\text { Surface area } \\
\text { BET } \mathrm{m}^{2} / \mathrm{g}\end{array}$ & Pore size, $\mathrm{nm}$ & CI & L $002, \mathrm{~nm}$ & DP \\
\hline MCC & 3.6 & 2.9 & 0.70 & 3.1 & 815 \\
MFC & 15.1 & 4.6 & 0.78 & 3.0 & 178 \\
NCC & 41.8 & 3.1 & 0.69 & 2.7 & 109 \\
\hline
\end{tabular}

The controlled sulfuric acid hydrolysis of MCC obtained by catalytic peroxide delignification of larch wood and subsequent ultrasonic treatment lead to an increase in the surface area of NCC formed more than 10 times compared to the original MCC (Table 7).

As a result of the accomplished study, new methods have been developed for the production of NFC and NCC from larch wood based on the use of catalytic peroxide oxidation process. These methods reduce the number of technological stages and increase the environmentally safety of nanocelluloses production from wood compared to traditional technologies.

\subsubsection{Composition of soluble products of larch wood peroxide fractionation}

The main amount of larch wood hemicelluloses is dissolved during catalytic peroxide oxidation of wood at $100{ }^{\circ} \mathrm{C}$. They were isolated from the reaction mixture by precipitation with ethanol. The yield of hemicelluloses reaches to $78 \mathrm{wt} \%$ from their initial content in larch wood (21.4 wt\% from wood). It is known that molybdenum catalysts are active in reactions of oxidative destruction of organic compounds by hydrogen peroxide [59]. The catalytic effect is achieved due to the formation of molybdenum peroxocomplexes which are strong oxidizing agents [59]. The active radicals formed during catalytic peroxide oxidation of lignin intensify the reactions of oxidative demethylation, oxidative opening of aromatic ring, displacement of the propane chain and cleavage of aryl ether bonds [60]. With participation of these reactions the oxidative depolymerization of lignin takes place with formation of low molecular weight organic compounds.

The composition of soluble products formed in the process of larch wood peroxide oxidation at $100{ }^{\circ} \mathrm{C}$ in the presence of catalyst $\left(\mathrm{NH}_{4}\right)_{6} \mathrm{Mo}_{7} \mathrm{O}_{24}$ was identified by GC-MS (Table 8). 


\section{Table 8}

Organic compounds in acetone extract of soluble products of larch wood peroxide oxidation at $100{ }^{\circ} \mathrm{C}$ in the presence of catalyst $\left(\mathrm{NH}_{4}\right)_{6} \mathrm{Mo}_{7} \mathrm{O}_{24}$

\begin{tabular}{lc}
\hline \multicolumn{1}{c}{ Compound } & Relative content, $\%^{*}$ \\
\hline Hydroxyacetic acid & 13.03 \\
Acetic acid & 48.50 \\
Levulinic acid & 2.96 \\
Succinic acid & 3.85 \\
Glutaric acid & 2.12 \\
Fumaric acid & 5.96 \\
Adipic acid & 4.32 \\
Vanillic acid & 2.64 \\
4-hydroxybenzoic acid & 2.61 \\
Unidentified & 14.01 \\
\hline
\end{tabular}

*from the sum of the areas of all peaks

Soluble products contain one and dibasic carboxylic and aromatic acids. The yield of soluble products reaches $20 \%$ on wood weight.

Hemicelluloses formed in the process of larch wood peroxide oxidation can be used to produce of $\mathrm{C}_{5}$ and $\mathrm{C}_{6}$ sugars that are widely used in various fields, including chemical synthesis [61]. The data on composition and concentrations of monosugars, which are formed in the process of hydrolysis of larch wood hemicelluloses by $2 \% \mathrm{HCl}$ at $100{ }^{\circ} \mathrm{C}$ are given in Table 9 .

\section{Table 9}

Composition and concentration of monosugars in hydrolyzate of hemicelluloses of larch wood (GC data)

\begin{tabular}{lcc}
\hline & Compound & Concentration, $\mathrm{mg} / \mathrm{g}$ \\
\hline Arabinose & 0.18 \\
Xylose & 0.32 \\
Galactose & 4.65 \\
Mannose & 2.12 \\
Glucose & 1.07 \\
\hline
\end{tabular}

Hydrolysis conditions: $100{ }^{\circ} \mathrm{C}, 2 \% \mathrm{HCl}$, time $3 \mathrm{~h}$.

Integration of the considered catalytic processes of oxidative and acid conversions of wood biomass components makes it possible to offer the scheme of larch wood biorefinery to valuable chemical products (Fig. 7). 


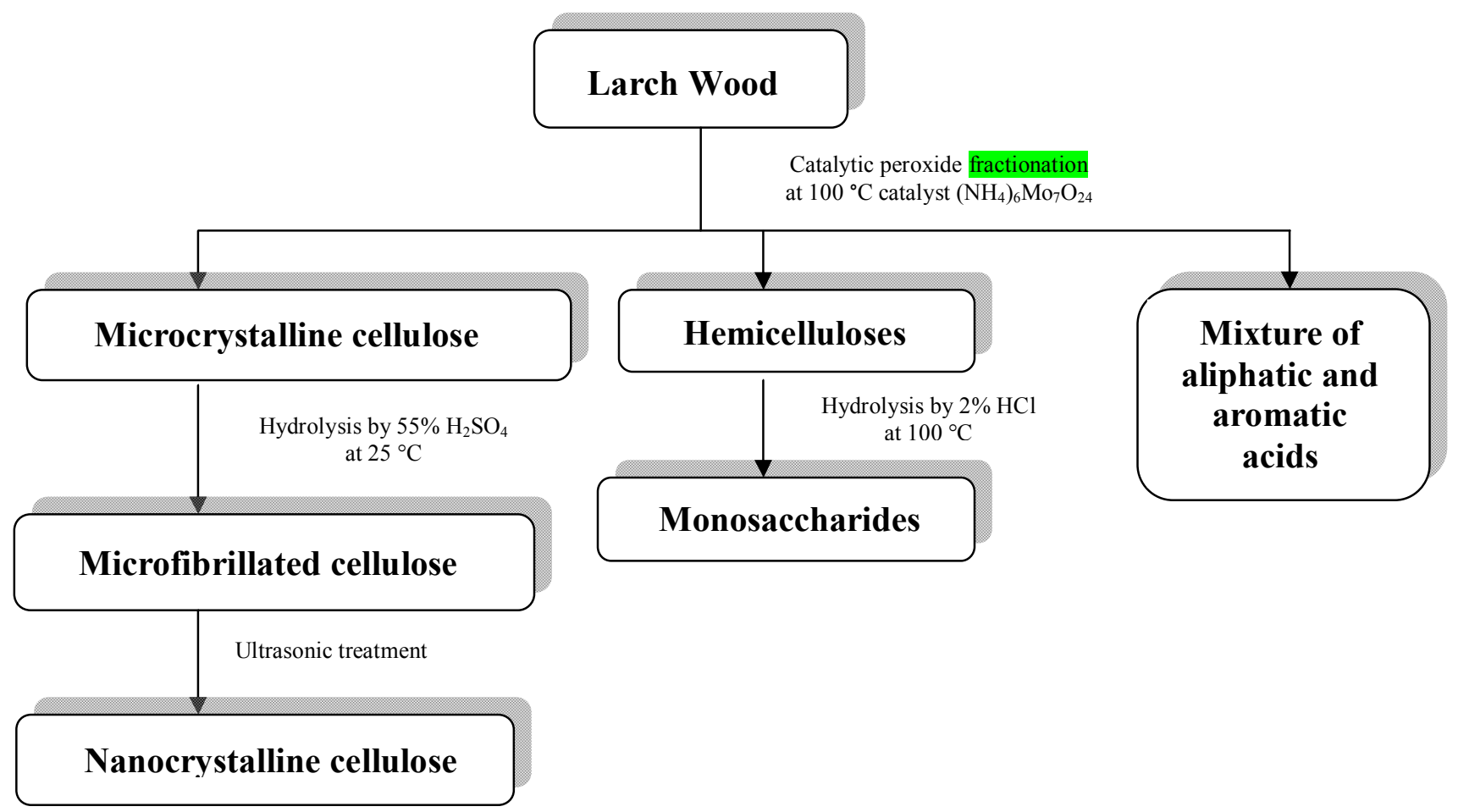

Fig.7. Larch wood biorefinery based on the process of catalytic peroxide oxidation

The developed biorefinery includes the stage of larch wood peroxide fractionation into MCC, organic acids and hemicelluloses. Catalytic hydrolysis and ultrasonic treatment of MCC produce MFC and NCC. Acid-catalysed hydrolysis of hemicelluloses produces $\mathrm{C}_{6}$ and $\mathrm{C}_{5}$ sugars (predominantly galactose, mannose and glucose).

\subsection{Production of chemicals by catalytic fractionation of softwood by oxygen}

\subsubsection{Yields of vanillin and levulinic acid}

Lignin is more easily oxidized compared to polysaccharides due to its phenolic nature. The features of lignin oxidation are determined by the nature of oxidant and by oxidation conditions $[62,63]$. Lignin degradation occurs by oxidation of propane chains and benzene rings. During the oxidation of lignin in alkaline medium propane chains and their bonds with aromatic ring are primarily destroyed and the latter retains the aromatic structure [34].

Catalyst can increase by 1.5-2 times the yield of aromatic aldehydes in the processes of lignins oxidation by oxygen [64]. These catalysts are presented by oxides and hydroxides of $\mathrm{Cu}(\mathrm{II}), \mathrm{Co}$ (III), Ag (I), Mn (IV). The most active catalysts are based on $\mathrm{Cu}(\mathrm{II})$.

In the present study we found that the vanillin yield in the oxidation of pine wood in the presence of catalyst $\mathrm{Cu}(\mathrm{OH})_{2}$ reaches to $18.6 \mathrm{wt} \%$ based on the initial lignin in wood. The cellulose yield after the oxidation of pine wood reaches to $84-93 \mathrm{wt} \%$, based on the initial cellulose amount in the wood. If the catalytic oxidation is targeted at the maximum vanillin yield 
(18 $\mathrm{wt} \%$ ), the cellulose yield decreases to $64 \mathrm{wt} \%$ of the initial amount. The best compromise is achieved with $17 \mathrm{wt} \%$ vanillin and $84 \mathrm{wt} \%$ cellulose yields based on the initial amounts of lignin and cellulose, respectively.

These results demonstrate the possibility of single-step catalytic fractionation of pine wood by oxygen into cellulose and vanillin. The cellulose yield exceeds $84 \mathrm{wt} \%$, and vanillin yield exceeds $70 \mathrm{wt} \%$ of the theoretical limit for the corresponding substance. The cellulose obtained in this oxidation process can be enzymatically hydrolyzed with up to $70 \%$ yield of reducing sugars, which can serve as feedstock for bioethanol production [65].

Catalytic oxidation of larch wood by oxygen in the presence catalyst $\mathrm{Cu}(\mathrm{OH})_{2}$ proceeds in a manner similar to pine wood. The yield of vanillin passes through a maximum with the increase of time of larch wood catalytic oxidation by $\mathrm{O}_{2}$ (Fig. 8). The subsequent sharp decrease in the yield of vanillin is due to reactions of its further oxidation.

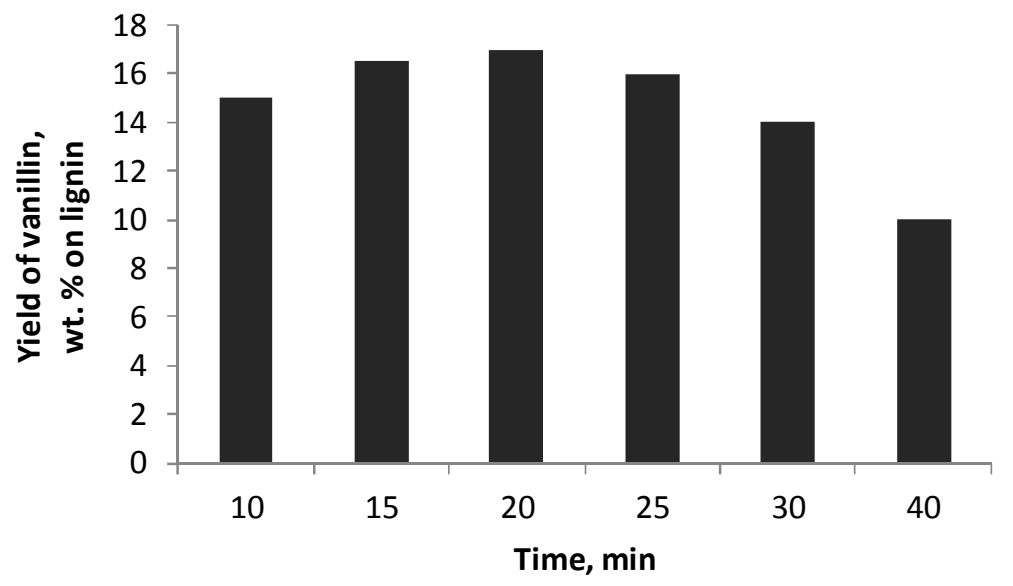

Fig. 8. Yield of vanillin in the process of larch wood oxidation by $\mathrm{O}_{2}$ in the presence of catalyst $\mathrm{Cu}(\mathrm{OH})_{2}$ at $170{ }^{\circ} \mathrm{C}$

The catalytic oxidation of larch wood by oxygen in water-alkaline medium makes it possible to fractionate the wood biomass into vanillin and cellulose product. The yield of cellulose product in the process of larch wood oxidation at $170{ }^{\circ} \mathrm{C}$ reaches to $38 \mathrm{wt} \%$ on abs. dry wood.

The catalyst $\mathrm{Cu}(\mathrm{OH})_{2}$ was recovered by the following way: the solid precipitate isolated from the reaction mixture by filtration was dissolved by treatment with hydrochloric acid (32 $w t \%)$. Then, copper hydroxide was precipitated from the solution with an alkali.

The acid-catalyzed conversion of cellulose product formed in the process of larch wood catalytic oxidation was studied. At optimized process conditions (temperature $180{ }^{\circ} \mathrm{C}$, concentration of $\mathrm{H}_{2} \mathrm{SO}_{4} 2 \%$, LWR 8 , time $3 \mathrm{~h}$ ) the yield of levulinic acid reaches to $28 \mathrm{wt} \%$ on abs. dry cellulose product (Fig. 9). 


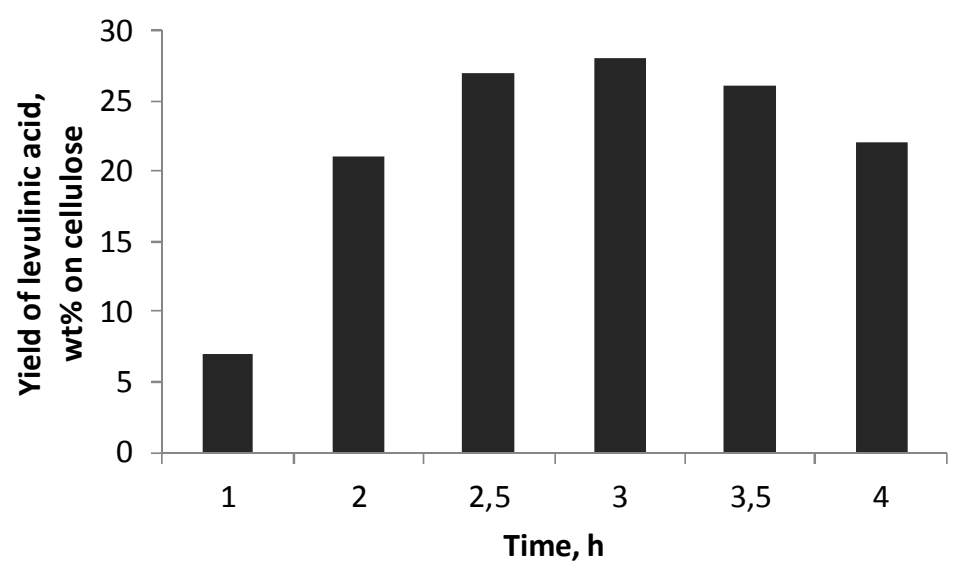

Fig. 9. Yield of levulinic acid in the process of acid-catalyzed conversion of cellulose from larch wood $\left(180{ }^{\circ} \mathrm{C}, 2 \% \mathrm{H}_{2} \mathrm{SO}_{4}\right.$, LWR 8$)$

\subsubsection{Larch wood biorefinery based on catalytic fractionation of wood by $\mathrm{O}_{2}$}

Larch wood contains near $2.5 \mathrm{wt} \%$ of flavonoids and about $20 \mathrm{wt} \%$ of polysaccharide arabinogalactan. The content of dihydroquercetin (DHQ) reaches $90 \%$ on the total amount of flavonoids. The known methods of DHQ isolation are based on the larch wood extraction by organic solvents, mainly by ethyl acetate and acetone. Organic solvents extract resinous substances together with DHQ, which contaminate the dihydroquercetin.

A new green method of one-step isolation of DHQ and AG by water-ethanol extraction of larch wood provides the simultaneous production of DHQ and AG, which are not contaminated with resinous substances [40]. The optimum ethanol concentration which provides a high yield of DHQ (1.8 wt\%) and AG (18.0 wt \%) corresponds to $15 \%$.

The average molecular weight of arabinogalactan sample, obtained at optimal conditions of larch wood extraction by ethanol-water mixture, determined by gel permeation chromatography is varied in the range of 7.95-14.10 kDa, corresponding to the degree of polymerization (DP) of 60-107. These DP values are smaller to those observed for the samples of AG isolated from Norway spruce heartwood (DP of 130-140) and from Scots pine heartwood (DP of 190-200) [66].

The main chain of the AG macromolecule consists of galactose units and the side chains include both galactose and arabinose units. Acid hydrolysis of AG is used for production of Dgalactose and L-arabinose, which are in demand as special sugars in pharmaceutical, cosmetic industries, in medicine etc. [67,68].

Enzymatic hydrolysis allows to produce monosaccharides by environmentally friendly way. However, in order to increase the enzymatic digestibility of polysaccharides the permanent processes should be used $[69,70]$. At present, in the industrial processes of acid-catalyzed hydrolysis of polysaccharides to monosugar the toxic and corrosion-active mineral acids are used 
as catalysts. Solid catalysts can become an alternative to mineral acids if they exhibit a sufficiently high activity, selectivity and stability in aquatic media [71].

In the present work the catalytic properties of soluble acid catalyst $\left(0.1 \mathrm{M} \mathrm{H}_{2} \mathrm{SO}_{4}\right)$ and acid modified solid catalysts SBA-15 and Sibunit 4 were compared in the process of arabinogalactan hydrolysis.

The complete hydrolysis of AG (corresponds to concentration of monosaccharides in hydrolizate near $4 \mathrm{~g} / \mathrm{l}$ ) is achieved in the presence of sulfuric acid catalysts at temperature $100{ }^{\circ} \mathrm{C}$ during $6 \mathrm{~h}$, and in the case of solid acid catalysts - at $150{ }^{\circ} \mathrm{C}$ during $5 \mathrm{~h}$ (Fig. 10).
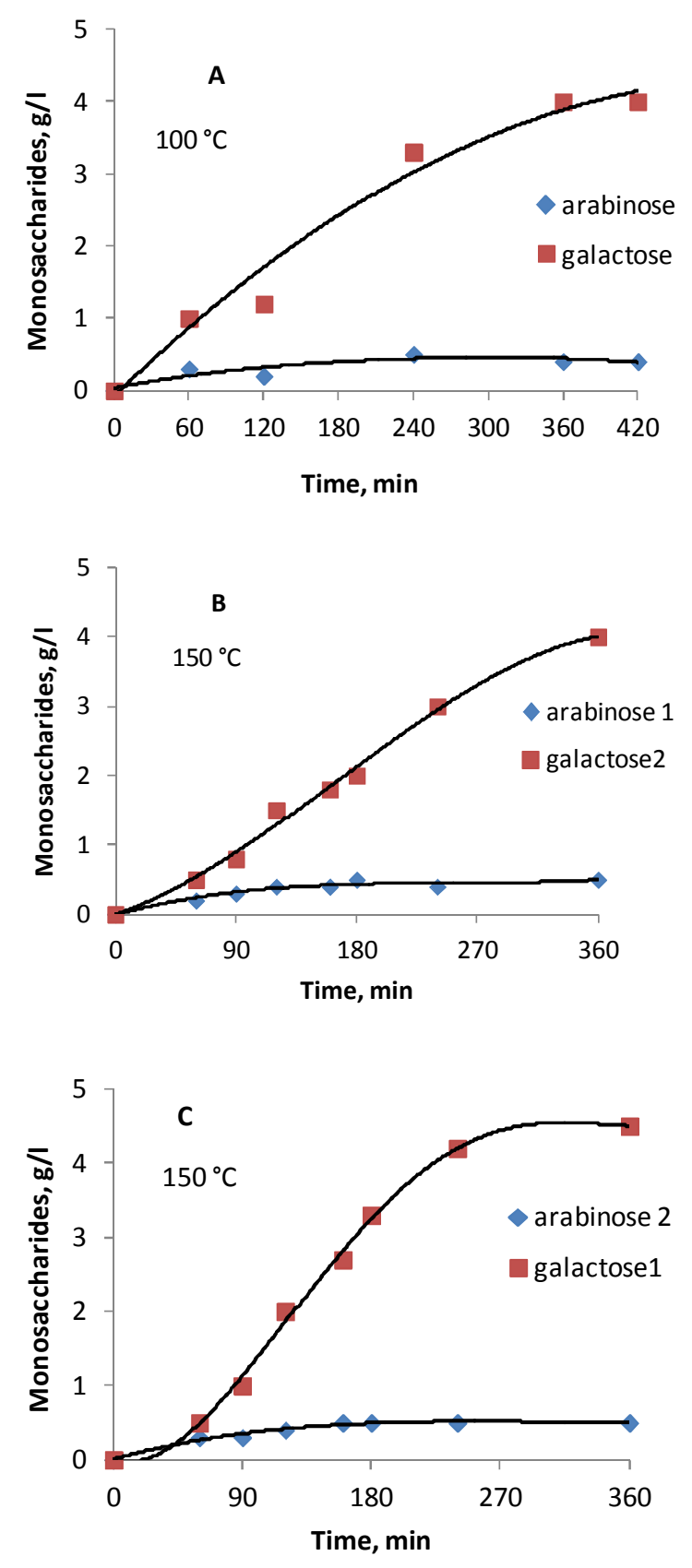

Fig. 10. Arabinogalactan hydrolysis in the presence of $0.1 \mathrm{M} \mathrm{H}_{2} \mathrm{SO}_{4}$ (A), acid-modified Sibunit-4 (B) and acid-modified SBA-15 (C) catalysts 
It was established, that acid-modified catalyst Sibunit-4 retains its activity in the process of $\mathrm{AG}$ hydrolysis at $150{ }^{\circ} \mathrm{C}$ for 3 catalytic cycles. Concentrations of arabinogalactan and galactose in hydrolizates of AG do not decrease after 12 hours of catalyst operation at temperature $150^{\circ} \mathrm{C}$ (Fig. 11).
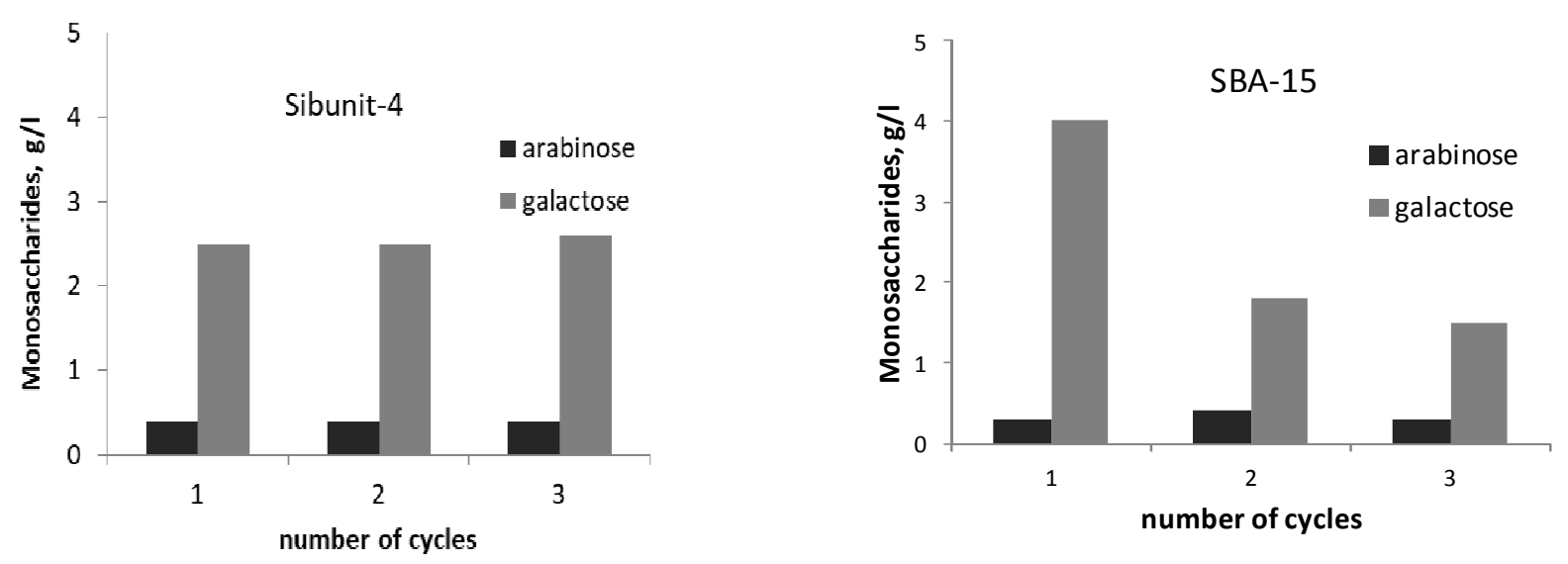

Fig. 11. Stability of solid acid-modified catalysts in the process of arabinogalactan hydrolysis at $150^{\circ} \mathrm{C}$

Acid-modified catalyst SBA-15 is less stable in the process of AG hydrolysis at $150{ }^{\circ} \mathrm{C}$. In the presence of this catalyst the concentration of monosugars in hydrolyzate decreased after the second and third catalytic cycles (Fig. 11). With an increase in time of catalyst operation a change in its structural characteristics is observed.

The surface area, pore volume and average pore size of spent catalyst SBA-15 increase from 495 to $604 \mathrm{~m}^{2} / \mathrm{g}$, from 0.59 to $1.02 \mathrm{~cm}^{3} / \mathrm{g}$ and from 4.7 to $6.8 \mathrm{~nm}$, respectively. The amount of acid groups decreases from 0.41 to $0.09 \mathrm{mmol} / \mathrm{g}$ compared to the fresh catalyst. So, the leaching of catalyst SBA-15 takes place in the process of AG hydrolysis in water medium at 150 ${ }^{\circ} \mathrm{C}$.

In the process of AG hydrolysis the solid catalyst Sibunit-4 and SBA-15 were separated from the reaction mixture by filtration.

By integrating the considered processes of catalytic conversion of the main components of larch wood it is possible to implement a complex processing of wood biomass into a number of valuable chemical products.

Earlier we described the process of larch wood biorefinery based on integration of stages of extraction isolation of arabinogalactan and dihydroquercetin and catalytic peroxide fractionation of its biomass with production of microcrystalline cellulose, sulfated functional polymers of MCC and AG, nanoporous materials from organosolv lignin [40].

The new approach to larch wood biorefinery includes the processes of AG and DHQ, extraction from wood, catalytic oxidation of extracted wood by $\mathrm{O}_{2}$ with obtaining vanillin and 
cellulose, acid-catalyzed conversion of cellulose to levulinic acid and hydrolysis of AG to galactose and arabinose (Fig. 12)

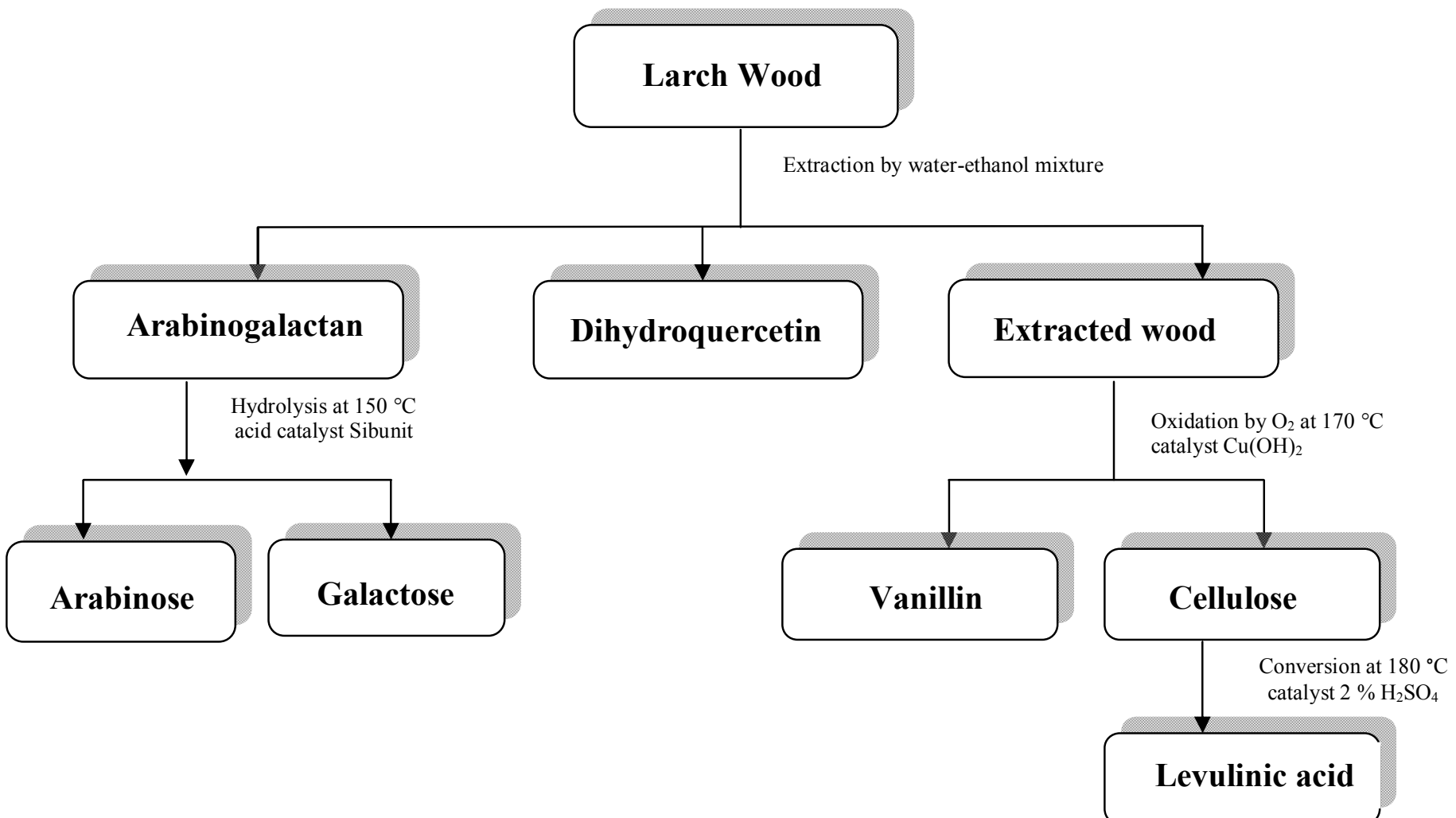

Fig. 12. Larch wood biorefinery based on catalytic fractionation of wood by oxygen

The proposed new processes of softwood biorefinery have a number of advantages over traditional pulp and hydrolysis technologies. These processes provide a comprehensive processing of all the main components of wood biomass to obtain a set of valuable chemical products. The cost of producing the target products vanillin or nanocelluloses is reduced if at the same time it is possible to obtain additional products with high added value (for example, biologically active dihydroquercetin and arabinogalactan). The use of "green" and low-toxic reagents (water, oxygen, hydrogen peroxide, acetic acid, ethanol) in new processes of wood biorefinery reduces the cost of environmental protection.

The possibility of using alternative scheme for biorefinery of larch wood (see Fig. 7 and Fig. 12) makes possible to diversity products taking into account current market needs.

The products of larch wood biorefinery (microcrystalline, microfibrillated and nanocrystalline celluloses, vanillin, dihydroquercetin, arabinogalactan, monosaccharides and organic acids) are in demand in medicine, chemical, pharmaceutical, food, cosmetic and perfumery industries $[9,10,25,72]$. 
To illustrate economic prospects of the processes suggested Table 10 presents the data on global production and prices of the relevant products. The global vanillin market amasses 15-20 thousand tons annually at the price 10-15 USD/kg, and global price of levulinic acid is worth around 3 USD/kg [24]. Market value estimate of these products from one ton of larch wood processed according to the suggested approach attains 800-1000 USD. This value may be exceeded if parallel production of dihydroquercetin and arabinogalactan is implemented. Unfortunately, the market prices of the latter two products are not stable and available now. For comparison, value of the cellulose alone obtained from that wood is 300-400 USD.

Market of micro- and nanocrystalline cellulose exceeds 130000 tons in 2018 [73 - 75], and prices of these products vary from 1.5 [76] to $150 \mathrm{USD} / \mathrm{kg}$ (Table 5). The latter indicates that value of such products from one ton of larch wood may exceed 5.000-7.000 USD.

\section{Table 10}

Market figures for the products of larch wood processing

\begin{tabular}{|c|c|c|c|c|}
\hline Substance & $\begin{array}{l}\text { Price, } 10^{3} \\
\text { USD } / \mathrm{t}\end{array}$ & $\begin{array}{l}\text { Global } \\
\text { production, } \\
10^{3} \mathrm{t}\end{array}$ & $\begin{array}{l}\text { Yield from one } \\
\text { ton of wood, } \mathrm{kg}\end{array}$ & $\begin{array}{l}\text { Value of the product } \\
\text { from one ton of } \\
\text { wood, USD }\end{array}$ \\
\hline Vanillin & $10-15$ & $15-20$ & 47 & $470-700$ \\
\hline Levulinic acid & 3 & $2-5$ & 97 & 290 \\
\hline Cellulose & 1.0 & 400000 & 380 & 380 \\
\hline $\begin{array}{l}\text { Microcrystalline } \\
\text { cellulose }\end{array}$ & $7.5-20$ & 120 & 350 & $2600-7000$ \\
\hline Nanocellulose & 150 & 0.4 & 37 & 5500 \\
\hline $\begin{array}{l}\text { Cellulose micro- and } \\
\text { nanofibrils (CMNF) }\end{array}$ & $1.5-1.9$ & 12 & 75 & $110-150$ \\
\hline Arabinogalactan & $10-50$ & - & 180 & $1800-9000$ \\
\hline
\end{tabular}

\section{Conclusion}

Two alternative routes of larch wood oxidative fractionation for the production of chemicals have been suggested. The one of them is based on peroxide oxidation in the presence of soluble catalyst $\left(\mathrm{NH}_{4}\right)_{6} \mathrm{Mo}_{7} \mathrm{O}_{24}$ to produce microcrystalline, microfibrillated, nanocrystalline celluloses, monosaccharides and mixture of aliphatic and aromatic acids.

The another route is based on the larch wood oxidation by oxygen in the presence of catalyst $\mathrm{Cu}(\mathrm{OH})_{2}$ to produce vanillin and cellulose. By acid-catalysed conversion of cellulose the levulinic acid is obtained.

The preliminary extraction of larch wood with water-ethanol mixture allow to produce biologically active dihydroquercetin (DHQ) and arabinogalactan (AG). By catalytic hydrolysis of AG over solid acid catalyst Sibunit the arabinose and galactise are obtained. 
The developed processes use non-toxic and less-toxic reagents, such as water, oxygen, hydrogen peroxide, acetic acid and ethanol. The resulting products are in demand in many areas, including food, pharmaceutical, chemical industries, medicine, syntheses of new functional polymers and nanocomposites

\section{Funding}

The reported study was supported by Russian Science Foundation, Grant No. 16-13-10326.

\section{Declarations of interest}

None

\section{Acknowledgements}

The equipment of Krasnoyarsk Regional Research Equipment Centre of SB RAS was used in present work. The authors acknowledge E.V. Mazurova for SEM measurements, A.A. Karacharov for AFS measurements and A.A. Kondrasenko for NMR measurements.

\section{References}

1. R.M. Rowell, Handbook of wood chemistry and wood composites, 2nd edn. CRC Press, Boca Raton, 2012, $592 \mathrm{p}$

2. E. Sjöström, Wood chemistry - fundamentals and applications, 2nd edn. Academic Press, New Work, 1993, $293 \mathrm{p}$

3. H. Sixta, Handbook of pulp, Wiley-VCH Verlag GmbH \& Co, Weinheim. 2006, 1352 p.

4. P. Bajpai, Biorefinery in the pulp and paper industry, Academic Press. Elsevier. 2013. $114 \mathrm{p}$, https://doi.org/10.1016/C2012-0-06724-5

5. H. Amiri, K. Karimi, Efficient dilute-acid hydrolysis of cellulose using solvent pretreatment. Industrial \& Engineering Chemistry Research. 52 (2013) 11494-11501, https://dx.doi.org/10.1021/ie4017368

6. M. Bessone, P. Gallezot, C. Pinel, Conversion of biomass into chemicals over metal catalysts, Chem Rev. 114 (2014) 827-1870, http://doi: 10.1021/cr4002269

7. J.C. Serrano-Ruiz, J.A. Dumesic, Catalytic routes for the conversion of biomass into liquid hydrocarbon transportation fuels, Energy Environ. Sci. 4 (2011) 83-99, https://doi.org/10.1039/C0EE00436G

8. Y. Jing, Y. Guo, Q. Xia, X. Liu, Y. Wang, Catalytic production of value-added chemicals and liquid fuels from lignocellulosic biomass, Chem. 5 (2019) 1-27, DOI: 10.1016/j.chempr.2019.05.022

9. D. A. Bulushev, J.R.H. Ross, Catalysis for conversion of biomass to fuels via pyrolysis and gasification: A review, Catal. Today 171 (2011) 1-13, doi:10.1016/j.cattod.2011.02.005

10. J. Horacek, F. Homola, I. Kubickova, D. Kubicka, Lignin to liquids over sulfide catalysts, Catal. Today 179 (2012) 191-198, doi:10.1016/j.cattod.2011.06.031

11. M. Suchy, D. Argyropoulos, Catalysis and activation of oxygen and peroxide delignification of chemical pulps: a review, ACS SympSer. 785 (2001) 2-43, DOI: 10.1021/bk-2001-0785.ch001

12. K. Dussan, B. Girisuta, D. Haverty, J.J. Leahy, M.H. Hayes, The effect of hydrogen peroxide concentration and solid loading on the fractionation of biomass in formic acid, Carbohydr. Polym. 111 (2014) 374-384, DOI:10.1016/j.carbpol.2014.04.039 
13. S. Das, D. Lachenal, N. Marlin, Production of pure cellulose from Kraft pulp by a totally chlorine-free process using catalyzed hydrogen peroxide, Ind Crops Prod. 49 (2013) 844850, DOI: $10.1016 /$ j.indcrop.2013.06.043

14. M. Lucas, S.K. Hanson, G.L. Wagner, D.B. Kimball, Evidence for room temperature delignification of wood using hydrogen peroxide and manganese acetate as a catalyst, Bioresour. Technol. 119 (2012) 174-180, doi: 10.1016/j.biortech.2012.05.086.

15. G. Ramadoss, K. Muthukumar, Influence of dual salt on the pretreatment of sugarcane bagasse with hydrogen peroxide for bioethanol production, Chem. Eng. J. 260 (2015) 178-187, DOI: $10.1016 /$ j.cej.2014.08.006

16. T. Voitl, P. R. von Rohr, Oxidation of lignin using aqueous polyoxometalates in the presence of alcohols, ChemSusChem. 1 (2008) 763 - 9, doi: 10.1002/cssc.200800050

17. A. Rodriguez, L. Jimenez, Pulping with organic solvents other than alcohols, Afinidad 65(535) (2008) 188-196.

18. P. Ligero, A.Vega, J.J. Villaverde, Delignification of Miscanthus $\times$ giganteus by the milox

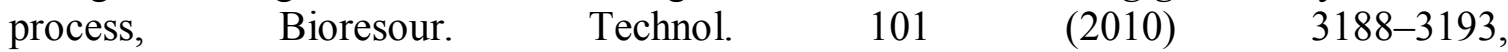
DOI: 10.1016/j.biortech.2009.12.021.

19. B.N. Kuznetsov, S.A. Kuznetsova, V.G. Danilov, O.V. Yatsenkova, A.V. Petrov, A green one-step process of obtaining microcrystalline cellulose by catalytic oxidation of wood, Reac. Kinet. Mech. Cat. 104 (2011) 337-343, DOI: 10.1007/s11144-011-0354-8.

20. N. Nwachukwu, S.I. Ofoefule,Effect of drying methods on the powder and tableting properties of microcrystalline cellulose obtained from Cocosnucifera,J. of Pharmaceutical Research Int. (JPRI) 20(2)(2017) 1-15, DOI: 10.9734/JPRI/2017/37615.

21. G. Thoorens, F. Krier, B. Leclerq, B. Carlin, B. Evrard, Microcrystalline cellulose, a direct compression binder in a quality by design environment. A review, Int. J. Pharm. 473 (2014) 64-72, doi: 10.1016/j.ijpharm.2014.06.055.

22. M. George, C. Montemagno, Cellulose based materials: in-depth property survey and assessment, Int. Refereed Journal of Engineering and Science (IRJES) 6(5) (2017) 5576.

23. F.V. Ferreira, M. Mariano, S.C. Rabelo, R.F. Gouveia, L.M.F. Lona, Isolation and surface modification of cellulose nanocrystals from sugarcane bagasse waste: From a micro- to a nano-scale view,Appl. Surf. Sci. 436 (2018) 1113-1122, doi: 10.1016/j.apsusc.2017.12.137.

24. V.E. Tarabanko, N.V.Tarabanko, Catalytic oxidation of lignins into the aromatic aldehydes: general process trends and development prospects, Int. Journal of mol. Sci. 18(11) (2017) 2421, doi:10.3390/ijms18112421.

25. C.Z. Li, X.C. Zhao, A.Q. Wang, G.W. Huber, T. Zhang, Catalytic transformation of lignin for the production of chemicals and fuels, Chem. Rev. 115 (2015) 11559-11624, DOI: 10.1021/acs.chemrev.5b00155.

26. H.S. Horhammer, T.H. Treasure, R.W. Gonzalez, A.R.P. Heiningen, Larch biorefnery: technical and economic evaluation, Ind. Eng. Chem. Res. 53 (2014) 1206-1213, https://doi.org/10.1021/ie403653j.

27. B. Mercier, J. Prost, M. Prost, The essential oil of turpentine and its major volatile fraction ( $\alpha$-and $\beta$-pinenes): a review, Int J Occup Med Environ Health 22(4) (2009) 331342, DOI: 10.2478/v10001-009-0032-5.

28. E. Sjöström, R. Alern, Analytical Methods of Wood Chemistry. Pulping and Papermaking, Springer-Verlag, Berlin, 1999, 318 p.

29. K.A. Sashkina, E.V. Parkhomchuk, N.A. Rudina, V.N. Parmon, The role of zeolite FeZSM-5 porous structure for heterogeneous Fenton catalyst activity and stability, $\begin{array}{lllll}\text { Microporous } & \text { Mesoporous } & \text { Mater. } & 189 & \text { (2014) }\end{array}$ http://dx.doi.org/10.1016/j.micromeso.2013.11.033.

30. O.P. Taran, E.M. Polyanskaya, O.L. Ogorodnikova, C. Descorme, M. Besson, V. Parmon, Sibunit-based catalytic materials for the deep oxidation of organic ecotoxicants 
in aqueous solution: I. Surface properties of the oxidized Sibunit samples, Catal. Ind., 2(4) (2010) 381-386, https://doi.org/10.1134/S2070050410040136.

31. J. Pang, A. Wang, M. Zheng, T. Zhang, Hydrolysis of cellulose into glucose over carbons sulfonated at elevated temperatures, Chem. Commun. 46 (2010) 6935-6937, https://doi.org/10.1039/C0CC02014A.

32. J.A. Melero, R. Grieken, G. Morales, Advances in the synthesis and catalytic applications of organosulfonic-functionalized mesostructured materials, Chem. Rev. 106 (2006) 37903812, https://doi.org/10.1021/cr050994h.

33. B.N. Kuznetsov, I.G. Sudakova, N.V. Garyntseva, L. Djakovitch, C. Pinel, Kinetic studies and optimization of abies wood fractionation by hydrogen peroxide under mild conditions with $\mathrm{TiO}_{2}$ catalyst, Reac. Kinet. Mech. Cat. 120 (2017) 81-94, DOI: $10.1007 / \mathrm{s} 11144-016-1100-\mathrm{z}$.

34. V.E. Tarabanko, K.L. Kaygorodov, E.A. Skiba, N. Tarabanko, Yu.V. Chelbina, O.V. Baybakova, B.N. Kuznetsov, L. Djakovitch, Processing pine wood into vanillin and glucose by sequential catalytic oxidation and enzymatic hydrolysis, J. Wood Chem. Technol. 37(1) (2017) 43-51, http://dx.doi.org/10.1080/02773813.2016.1235583.

35. J. Gullichsen, C.J. Fogelholm, Chemical pulping, papermaking science and technology book 6B.Tappi Press, Finland, 2000, 497 p.

36. Tappi, Acid-insoluble lignin in wood and pulp. Standard T 222 Om-98. Technical association of the pulp and paper industry, Atlanta, 1998, $5 \mathrm{p}$.

37. ASTM D1795 Standard Test method for intrinsic viscosity of cellulose. ASTM International, West Conshohocken, PA, 2013, 6 p.

38. H. Pala, M. Mota, F.M. Gama, Enzymatic depolymerisation of cellulose, Carbohydr. Polym. 68 (2007) 101-108, doi:10.1016/j.carbpol.2006.07.015.

39. S. Park, J.O. Baker, M.E. Himmel, P.A. Parilla, D.K. Jonson, Cellulose crystallinity index: measurement techniques and their impact on integrating cellulose performance, Biotechnol Biofuels 3 (2010) 10, doi: 10.1186/1754-6834-3-10.

40. B.N. Kuznetsov, I.G. Sudakova, N.V. Garyntseva, V.A. Levdansky, N.M. Ivanchenko, A.V. Pestunov, L. Djakovitch, C. Pinel, Green biorefinery of larch wood biomass to obtain the bioactive compounds, functional polymers and nanoporous materials, Wood Sci. Technol. 52 (2018) 1377-1394, https://doi.org/10.1007/s00226-018-1029-7.

41. G.A. Smook, Handbook for Pulp and Paper Technologists. Vancouver (Canada): Angus Wilde Publications, 2002, 447 p.

42. S. Shankar, J.W. Rhim, Preparation of nanocellulose from microcrystalline cellulose: the effection the performance and properties of agar based composite films, Carbohydr. Polym. 135 (2016) 18-26, https://doi.org/10.1016/j.carbpol.2015.08.082.

43. P. Yuvraj, R.S. Chauhan, V.S. Sapkal, G.S. Zamre, Microcrystalline cellulose from cotton rags (Waste from garment and hosiery industries).Hydrogels for medical applications fabricated byoxidative-hydrolytic modification of cellulose, Int. J. Chem. Sci. 7(2) (2009) 681-688.

44. J.I. Moran, V.A. Alvarez, V.P. Cyras, A. Vazquez, Extraction of cellulose and preparation of nanocellulose from sisal fibers, Cellulose 15 (2008) 149-159, https://doi.org/10.1007/s10570-007-9145-9.

45. H. Wikberg, S.L. Maunu, Characterization of thermally modified hard- and softwoods by ${ }^{13} \mathrm{C}$ CPMAS NMR, Carbohydr. Polym. 58 (2004) 461-466, https://doi.org/10.1016/j.carbpol.2004.08.008.

46. G. Zuckerstätter, G. Schild, P. Wollboldt, T. Röder, H.K. Weber, H. Sixta, The elucidation of cellulose supra molecular structure by ${ }^{13} \mathrm{C}$ CP-MAS NMR, Lenzing. Ber. 87 (2009) 38-46.

47. H.V. Lee, S.B.A Hamid, S. K. Zain,Conversion of Lignocellulosic Biomass to Nanocellulose: Structure and Chemical Process,Scientific World Journal, Article ID 631013, 2014, 20 p, doi.org/10.1155/2014/631013. 
48. T. Isogai, M. Yanagisawa, A. Isogai, Degrees of polymerization (DP) and DP distribution of dilute acid-hydrolyzed products of alkali-treated native and regenerated celluloses, Cellulose 15(6) (2008) 815-823, doi:10.1007/s10570-008-9231-7.

49. H. Häkansson, P. Ahlgren, Acid hydrolysis of some industrial pulps: effect of hydrolysis conditions and raw material, Cellulose 12 (2005) 177-183, DOI: 10.1007/s10570-0041038-6.

50. W. Li, R. Wang, S. Liu, Nanocrystalline cellulose prepared from softwood kraft pulp via ultrasonic-assisted acid hydrolysis, Bioresources 6(4) (2011) 4271-4281, doi: $10.15376 /$ biores.6.4.4271-4281.

51. F.I. Ditzel, E. Prestes, B.M. Carvalho, I.M. Demiate, L.A. Pinheiro, Nanocrystalline cellulose extracted from pine wood and corncob, Carbohydr. Polym. 157 (2017) 15771585, https://doi.org/10.1016/j.carbpol.2016.11.036.

52. S.A. Nascimento, C.A. Rezende, Combined approaches to obtain cellulose nanocrystals, nanofibrils and fermentable sugars from elephant grass, Carbohydr. Polym. 180 (2018) 38-45, https://doi.org/10.1016/j.carbpol.2017.09.099.

53. L.Y. Xiang, M.A.P. Mohammed, A.S. Baharuddin, Characterisation of microcrystalline cellulose from oil palm fibers for food applications, Carbohydr. Polym. 148 (2016) 1120, https://doi.org/10.1016/j.carbpol.2016.04.055

54. M. Fan, D. Dai, B. Huang, Fourier transform infrared spectroscopy for natural fibres. In: SalihSalih (ed) Fourier transform - materials analysis, In Tech, Rijeka, 2012, 260 p.

55. S. S. Z. Hindi, Nanocrystalline cellulose: synthesis from pruning waste of Zizyphusspinachristi and characterization, Nanoscience and Nanotechnology Research 4(3) (2017) 106114, doi: 10.12691/nnr-4-3-4.

56. X. Yang, F. Han, C. Xu, S. Jiang, L. Huang, L. Liu, Z. Xia, Effects of preparation methods on the morphology and properties of nanocellulose (NC) extracted from corn husk, Ind. Crops Prod. 109 (2017) 241-247, https://doi.org/10.1016/j.indcrop.2017.08.032

57. W. Chen, H. Yu, Y. Liu, Y. Hai, M. Zhang, P. Chen, Isolation and characterization of cellulose nanofibers from four plant cellulose fibers using a chemical-ultrasonic process, Cellulose 18 (2011) 433-442, doi: 10.1007/s10570-011-9497-z.

58. G.H.D. Tonoli, E.M. Teixeira, A.C. Correa, J.M. Marconcini, L.A. Caixeta, M.A. Pereira-da-Silva, L.H.C. Mattoso, Cellulose micro/nanofibres from Eucalýptus kraft pulp: Preparation and properties, Carbohydr. Polym. 89 (2012) 80-88, doi:10.1016/j.carbpol.2012.02.052.

59. M.S. Robelo, J.L. Colodette, V.M. Sacon, M.R. Silva, M.A.B. Azevedo, Molybdenum catalyzed acid peroxide bleaching of Eucalýptus kraft pulp, Bioresources 3(3) (2008) 881-897.

60. R. Ma, Y. Xu, X. Zhang, Catalytic oxidation of biorefinery lignin to value-added chemicals to support sustainable biofuel production, ChemSusChem. 8 (2015) 24-51https://doi.org/10.1002/cssc.201402503.

61. S.C. Zhang, J.H. Lan, Z.Q. Chen, G.C. Yin, G.X. Li, Catalytic synthesis of 2,5furandicarboxylic acid from furoic acid: trancformation from $\mathrm{C} 5$ platform to $\mathrm{C} 6$ derivatives in biomass utilizations, ACS Sustainable Chemistry \& Engineering 5(10) (2017) 9360-9369, https://doi.org/10.1021/acssuschemeng.7b02396

62. W. Den, V.K. Sharma, M. Lee, G. Nadadur, R.S. Varma, Lignocellulosic biomass transformations via greener oxidative pretreatment processes: Access to energy and value-added chemicals, Front Chem. 6 (2018) 14, doi:10.3389/fchem.2018.00141.

63. J. Zakzeski, F.L. Jongerius, B.M. Weckhuysen, Transition metal catalyzed oxidation of Alcell lignin, soda lignin, and lignin model compounds in ionic liquids, Green Chem. 12 (2010) 1225-1236, https://doi.org/10.1039/C001389G.

64. J.J. Bozell, Approaches to the selective catalytic conversion of lignin: agrand challenge for biorefinery development, Top Curr.Chem. 353 (2014) 229-256, doi: 10.1007/128_2014_535. 
65. V. E. Tarabanko, K. L. Kaigorodov, N.V. Koropachinskaya, Yu.V. Chelbina, Preparation of aromatic aldehydes from biobutanol production wastes, Chem. for Sustainable Dev. 20 (2012) 471-476.

66. S. Willför, J. Hemming, M. Reunanen, Ch. Eckerman, B. Holmbom, Lignans and lipophilic extractives in Norway spruce knots and stemwood,Holzforschung 57 (2003) 27-36 https://doi.org/10.1515/HF.2003.005

67. R. Schlief, A. Alhassan, J. Wiggins, W. Schumann, H. P. Niendorf, Safety of the galactose-based ultrasound contrast agent Levovist, Academic radiology 9(1) (2002) 240-2, https://doi.org/10.1016/s1076-6332(03)80446-4.

68. M. Helanto, K. Kiviharju, T. Granström, M. Leisola, A. Nyyssölä, Biotechnological production of L-ribose from L-arabinose, App. Microbiol. Biotechnol. 83 (2009) 77-83, https://doi.org/10.1007/s00253-008-1855-x.

69. S.H. Mood, A. M. Golfeshan, M. Tabatabaci, G.H. Jouzani, G.H. Najafi, M. Gholami, M. Ardjmand, Lignocellulosic biomass to bioethanol, a comprehensive review with a focus on pretreatment, Renew.Sust.Energ.Rev. 27 (2013) 77-93, https://doi.org/10.1016/j.rser.2013.06.033.

70. X. Zhao, K. Cheng, D Lin, Organosolv pretreatment of lignocellulosic biomass for enzymatic hydrolysis, App. Microbiol. Biotechnol. 82 (2009) 815-827, https://doi.org/10.1007/s00253-009-1883-1.

71. P. Sudarsanam, R. Zhong, S. Van den Bosch, S.M. Coman, V.I. Parvulescu, B.F. Sels, Functionalised heterogeneous catalysts for sustainable biomass valorization, Chem. Soc. Rev. 47(22) (2018) 8349-8402, doi: 10.1039/c8cs00410b.

72. D. Klemm, F. Kramer, S. Moritz, T. Lindström, M. Ankerfors, D. Gray, A. Dorris, Nanocelluloses: A new family of nature-based materials, Angew. Chem. Int. Ed. 50 (2011) 5438 - 5466,doi: 10.1002/anie.201001273.

73. Microcrystalline Cellulose (MCC) Market by Source Type and Application: Global Opportunity Analysis and Industry Forecast 2018 - 2025. Allied Market Research. Portland, October, 2018, 212 p.

74. Cellulose Powder Market - Global Industry Analysis, Size, Share, Growth, Trends and Forecast 2018 - 2025. Researchstore.biz. US, July, 2018, 99 p.

75. J. Miller, Nanocellulose: Producers, Products and Applications - A Guide for End Users. TAPPI, 2017. Updated Biobased Markets, Sept, 2018, 170 p.

76. C.A. de Assis, M.C. Iglesias, M. Bilodeau, D. Johnson, R. Phillips , M.S. Peresin , E.M. Bilek , O.J. Rojas , R. Venditti , R. Gonzalez, Cellulose micro- and nanofibrils (CMNF) manufacturing - financial and risk assessment, BIOFPR. 12 (2018) 251-264, https://doi.org/10.1002/bbb.1835 